\title{
Article \\ Optimization of Evacuation Warnings Prior to a Hurricane Disaster
}

\author{
Dian Sun ${ }^{1, *}$, Jee Eun Kang ${ }^{2}$, Rajan Batta ${ }^{2}$ and Yan Song ${ }^{1}$ \\ 1 School of Economics and Management, Harbin Engineering University, Harbin 150001, China; \\ songyan@hrbeu.edu.cn \\ 2 Industrial and Systems Engineering, University at Buffalo, Buffalo, NY 14260, USA; \\ jeeeunka@buffalo.edu (J.E.K.); batta@buffalo.edu (R.B.) \\ * Correspondence: sundian900621@163.com
}

Received: 27 October 2017; Accepted: 20 November 2017; Published: 22 November 2017

\begin{abstract}
The key purpose of this paper is to demonstrate that optimization of evacuation warnings by time period and impacted zone is crucial for efficient evacuation of an area impacted by a hurricane. We assume that people behave in a manner consistent with the warnings they receive. By optimizing the issuance of hurricane evacuation warnings, one can control the number of evacuees at different time intervals to avoid congestion in the process of evacuation. The warning optimization model is applied to a case study of Hurricane Sandy using the study region of Brooklyn. We first develop a model for shelter assignment and then use this outcome to model hurricane evacuation warning optimization, which prescribes an evacuation plan that maximizes the number of evacuees. A significant technical contribution is the development of an iterative greedy heuristic procedure for the nonlinear formulation, which is shown to be optimal for the case of a single evacuation zone with a single evacuee type case, while it does not guarantee optimality for multiple zones under unusual circumstances. A significant applied contribution is the demonstration of an interface of the evacuation warning method with a public transportation scheme to facilitate evacuation of a car-less population. This heuristic we employ can be readily adapted to the case where response rate is a function of evacuation number in prior periods and other variable factors. This element is also explored in the context of our experiment.
\end{abstract}

Keywords: hurricane disaster; evacuation warning; risk communication; evacuation decision-making; hurricane evacuation planning

\section{Introduction}

In 2012, Hurricane Sandy made landfall in the U.S. and inundated parts of New York City (NYC), which caused substantial loss of lives and property damage. At least 113 people were killed. Heavy rainfall, storm surge, high winds, inland flooding, fires and heavy snow were all recorded in association with Sandy, as up to 60 million people in 24 states were affected [1]. In order to reduce injury and mortality from hurricanes, the necessity of efficient evacuation management is well recognized. To facilitate efficient evacuation, public and private decision-makers need to account for risk and uncertainty during hurricanes and behavioral and managerial factors need to be controlled. A major problem encountered during hurricane evacuation is unexpected congestion, which reduces traffic flows, especially in metropolitan areas, and it can be catastrophic and life threatening [2,3]. The most notable lesson in this regard is that an evacuation plan can fail because of excessive reliance on automobiles, resulting in traffic congestion and fuel shortages [4]. Congestion can cause vehicles to run out of gas and create gridlock of the evacuation system, frustrating evacuees [5]. A study prescribed an evacuation plan which minimized the total congestion-related evacuation time [6]. 
Evacuation planning helps households make more informed and efficient decisions and also helps the government develop a well-planned strategy to improve efficiency of evacuation.

Understanding evacuee behavior is essential if an evacuation plan is to be successful [7]. People's decisions to evacuate are likely influenced by multiple factors and one of the challenges to those responsible for managing evacuations from hurricanes is how to best inform and direct the public's response to the pending emergencies [8]. Even though evacuees typically make decisions by themselves, they also often want to choose the most reliable way to protect their families. As many studies [9-12] indicated that in reality a share of travelers likely decides not to comply with the evacuation warnings. When they think those protective actions are unnecessary or are being initiated too soon [10], or want to protect their property [11], they are unlikely to comply with evacuation warnings. A study [12] concluded that the complex and somewhat bewildering phenomenon of why people sometimes decide not to evacuate from a dangerous situation is influenced by a combination of individual characteristics and three basic social psychological processes: (a) risk perception; (b) social influence; and (c) access to resources. Thus, people in evacuation zones may leave at different times or alternatively stay at home after they receive the warning messages. Good communication of risk during an evacuation is important so that the households not only get valuable information but also understand the risk they face, which could help them make suitable evacuation decisions. The process of risk communication of a hurricane involves sending different types of warnings over a period of time until the strike of the hurricane. The compliance of evacuation warnings may change over time and also will be affected by the sources of warnings. Based on the likelihood of evacuation after receiving different sources of warnings over time, we can predict, by zone, the number of people who will evacuate and when these peoples will depart, and thus make evacuation effective by controlling the warning system.

In this study, we assume that decision-makers have complete information on the response rate of evacuation when warnings are received from different sources in different time periods. In reality, this information comes from understanding evacuation behaviors. In the past decade, many researchers studied a multitude of evacuation behaviors extensively (see Section 2.2) that can provide evacuation response rates. Based on these response rates, we formulate a warning optimization problem that aims to optimize evacuation by managing congestion in the traffic network during the process of evacuation. The output of our model is an evacuation warning schedule.

The remainder of the paper is organized as follows. In Section 2, we provide a brief review of the relevant literature. In Section 3, we discuss model details related to shelter allocation and hurricane evacuation warning optimization. A case study of the proposed models is presented in Section 4 . Concluding remarks and future work considerations are offered in the last section.

\section{Literature Review}

The key components of this research are maximizing the number of evacuees and reducing congestion during hurricane evacuation by optimal utilization of the warning sources with strict time constraints. Therefore, in this section, we present separate reviews of the literature in the general area of hurricane evacuation planning and warnings.

\subsection{Hurricane Evacuation Planning}

A study reviewed the research of evacuation modeling and simulation over the past decade, which highlight the need of interdisciplinary efforts between social scientists and engineers in the future [13]. This study included major components of roadway transportation planning and operations and concluded that evacuation models should be based on the following aspects: evacuation warnings and information dissemination, zoning, demand modeling, traffic assignment and route selection, evacuation strategies and logistical issues. 
The mode of transportation taken to evacuate mainly depends on different population groups. The most traditional mode choice is to evacuate by private vehicle [14,15]. The main reason of choosing other modes is related to the unavailability of a personal vehicle (car-less population).

Lindell and Prater [16] revealed that evacuees who have personal vehicles are largely assumed to evacuate by themselves. The majority of studies on improving the efficiency of evacuation focus on traffic assignment. A research reviewed studies related to emergency evacuation planning and paid particular attention to the network design problem (NDP) since most strategies and approaches of evacuation planning can be formulated as an NDP [17]. The study [18] presents a capacitated network flow model to maximize the total evacuees for short notice evacuation planning represented by hurricanes. The approach is based on the time-expanded network, and, as a result, a decision-making tool is developed that deals with assigning evacuation routes, flows and schedules. NDP considers capacity constraints of evacuation networks necessary for evacuation planning. Background traffic is a factor that cannot be ignored, affecting the practical capacity of an evacuation network. An optimal zone-based vehicle evacuation strategy was developed based on an optimization-simulation approach, which included background traffic to simulate the traffic conditions [19]. It is noted that the use of a car to evacuate depends very much on the location of the nearest safe zone. A study used diurnal factors to convert average daily trip tables to average hourly trip tables and describe a hurricane evacuation model concerning the background demand obtained from the normal daily vehicle trips by hour [5].

Although most evacuees leave by taking their own cars, some researchers have investigated the needs for car-less populations and efficient use of public transportation since Hurricane Katrina [4,20-22]. A study that we specifically draw upon in our case study proposed a multistage approach for public transportation evacuation, formed by a planning framework and a model by using a simulation tool to simulate dispatching of the given number of buses, stochastic arrival of evacuees, queueing effects at the pickup locations, and the transportation of evacuees to safety regions [23]. This study only focuses on the public transportation, and provides a mass-evacuation strategy that serves as an evaluation tool for a route design. Our study also considers self-evacuation. By using a warning schedule, we integrate the multistage approach with the demand of public transportation, in order to help with evacuation planning.

Clearly, hurricanes are not the only natural disaster events that lead to mass evacuations. Another example of this are flood events, especially work from the Netherlands. For example, the work by Pengel et al. [24] discusses an urban flood warning system that monitors data from a variety of sources, including embankments, dikes, levees and dams. Such a system can be compiled with evacuation of flood prone areas.

\subsection{Hurricane Evacuation Warning}

Warnings are messages that are transmitted from a source via a channel to a receiver, so the message, source and channel can strongly influence evacuation behavior [25]. A warning source is the agency responsible for initiating hazard communication with the public. Sources can be government authorities, media figures, or peers such as friends and relatives [26].

According to extensive research in hurricane evacuation, receiving a warning is the main reason for people to make an evacuation decision. Clear and effective communication of evacuation orders is crucial to carrying out an evacuation [13]. In order to better manage hurricane evacuations, a study analyzed Hurricane Lili from the perspectives of household reliance on information sources, factors affecting their decisions to evacuate, timing of their hurricane evacuation decisions, and the time it takes them to prepare to evacuate [27]. Evacuation studies conducted over the past two decades have found that various population groups employ different sources to seek evacuation information [28]. Evacuees behavior were motivated by the Governor's official evacuation order, Weather Channel/ National Weather Service/local news, local officials' warnings, and actions/advice from peers [29]. During Hurricane Bret in 1999, television networks were found to be the most important source of information, followed by local radio broadcasts [30]. 
Advice and orders from officials strongly affects evacuation behavior, even though they receive information from public officials less frequently than from other sources, and a series of evacuation studies have proved that people are more likely to evacuate if they receive state or local official evacuation orders or if they receive threat assessments from a reputable weather channel such as the National Hurricane Center. A hurricane evacuation behavior survey was administrated in order to understand pre-hurricane evacuation decisions and communication preferences of residents [31]. They found that evacuees prefer leaving in the daytime rather than at night.

Studies emphasize the importance of multiple sources of information in studying evacuation behavior [32], stating that multiple information sources affirms an evacuation warning, thus coaxing an individual to evacuate [33].

In terms of the sources of hurricane information, the Weather Channel and numerous web sites provide forecasts and hurricane-related information around the clock [34]. Warnings can be received from the U.S. Weather Service, media outlets, peers (friends, relatives, neighbors, and coworkers), and government officials [35]. However, not every source has equal credibility, which results in different compliance of an evacuation order when people seek information from various sources.

In the U.S., the National Weather Service (NWS) of the National Oceanic and Atmospheric Administration (NOAA) issues hurricane watches, warnings, and several other hurricane-related alerts. The NWS issues a hurricane warning for an area when weather conditions for a hurricane are expected within $36 \mathrm{~h}$ [36], since the NWS sends weather warnings to phones and people will automatically pick up warnings by nearby cell towers [37]. The warnings from the NWS are authoritative and credible, which could help people make evacuation decisions.

Moreover, media outlets such as television, radio and newspapers are reported as the most important sources of hurricane information in previous studies, especially television broadcasts [30,38]. This is the most traditional way to obtain hurricane information, since it is considered to be high in expertise and trustworthiness [27]. However, one should note that the least effective approach was "issuing a bulletin through the media" according to the report conducted by the New York State Resiliency Institute for Storms and Emergencies [39].

Furthermore, social networks are another source that cannot be ignored, which means obtaining warning information from peers, through phone apps, social media, or word of mouth. Friends and families often are viewed as trustworthy sources [35], and social media has drawn attention in recent years due to its enhanced features in sharing information [40].

Last but not the least, the advice of state officials and local emergency managers has been among the key factors affecting people's decisions to evacuate [34]. If the danger is significant, state or local government officials may issue an evacuation notice, which could be mandatory or voluntary. Some studies indicate that travel door-to-door urging evacuation and explaining risk of remaining behind by using uniformed officers is the most effective way to communicate [39,41]. According to the report after Hurricane Sandy developed by the Mayor's Office with input from many NYC agencies, NYCHA (New York City Housing Authority) employees knocked on 3436 doors of residents who have special needs as well as the doors of 7680 seniors preceding the storm [42]. As an information channel, social media has also been used by officials for sending warning messages. The NYC sent more than 2000 tweets and gained more than 175,000 social media followers during Hurricane Sandy as the report showed [42]. In addition, local emergency management staff also praised the Weather Channel for public education and information, which provides a national and local weather forecast for cities, as well as weather radar, report and hurricane coverage [43].

In summary, there is considerable understanding of evacuation modeling from the perspective of communication strategies. In addition, many studies investigate utilization of evacuation warning sources and their potential impact on evacuation behavior during hurricanes. However, most studies focus on the effect of information sources on the decision-making of an evacuation and there is no investigation of how to use the warning sources in different time periods prior to the hurricane disaster. The at-risk public can be served by continuous education in order to make them understand the 
meaning of evacuation warning [39]. Our study develops a method to provide a schedule of sending evacuation warnings and also helps reduce congestion during a hurricane evacuation.

\subsection{Hurricane Evacuation Response Rate}

Evacuation demand can be predicted by using the response rate of evacuation if we have enough knowledge of the individuals' decision of evacuation such as evacuating or not and when to evacuate. This decision process is affected by multiple factors, such as the characteristics of a household [44-52], conditions in which they reside (e.g., income, type of house, vehicle ownership, time of day) $[49,50,53,54]$, warning time [55,56], perceived information [57-62] and personal risk perception [63-68].

In the field of evacuation behavior, a lot of studies agree that individuals make evacuation decisions according to how they perceive risk, and this is why the researchers take risk perception as the most prominent factor. A substantial number of empirical studies supported the fact that people would like to seek information, assess their personal risk, and make independent evacuation decisions rather than follow the advice and orders from public officials. This explains the need to improve our understanding of the type of reaction that this information triggers among evacuees.

Among the factors, the characteristics of the household show a significant effect on the evacuation decisions [44-50], including its timing [51,68], destination [28,67] and mode [52]. One reason is that the characteristics of the household are consistently associated with risk perception. A similar statement can be made about factors related to information. They all affect risk perception as risk is influenced by social dimensions and particular contexts [65]. According to the characteristics of the household, we divided the people into different groups (types), and each group has their own risk-perception rule.

Evacuation demand models should be sensitive to time-varying characteristics of a storm and the contextual conditions surrounding an evacuee [49]. Thus, the likelihood of people to evacuate also needs to consider the time dimension. For example, when people receive a warning at the beginning, they need more information to confirm the risk and more time to prepare evacuation, so the evacuation response rate is usually lower. On the contrary, if they receive a warning when the hurricane is within a few hours of landfall, the public risk perception is higher and usually leads to higher likelihood of evacuation. Therefore, the evacuation response rate distribution obeys an S-curve as postulated in many studies $[69,70]$.

We set up a response rate variable $p_{i j t}$ that related evacuee type $(i)$, sources of the information $(j)$ and time $(t)$ to represent risk perception level, which is the leading factor that influences evacuation behavior.

By using discrete choice theory, the sequential logit model is developed used to predict the share of people who will evacuate [53]. It relates time dependent factors to a sequence of choices made by an evacuee in multiple time periods. A study compared the time-dependent nested logit model and the time-dependent sequential logit model, concluding that the time-dependent nested logit model is superior [49]. In order to understand the causal factors that influence the household-level evacuation timing decision, the random parameters are used in a hazard-based modeling approach [68]. The study concluded that, in addition to environmental, social and demographic factors, risk perception is another key element to understanding the influence of warning response in an evacuation setting.

It is evident from the above discussion that we can reliably obtain $p_{i j t}$ values from evacuation behavior modeling studies. For our analysis, we assume perfect knowledge of $p_{i j t}$ values and further assume that these are deterministically known. To increase realism of our model, we allow $p_{i j t}$ to vary depending upon the evacuation outcomes of time periods. 


\section{Research Methodology}

\subsection{Notation}

Mathematical notation used in this paper is listed in Table 1. Type is defined as the kind of evacuees who evacuate by using a specific transportation mode. We use $i \in I$ to denote the types. Another index $j \in J$ is used to denote the information source. It is essential to clarify that $J$ is a combination of warning sources, which means that we could send evacuation warning messages through different sources at the same time. Furthermore, network $G=\left(N^{\prime}, A^{\prime}\right)$ represents the transportation network in the area of interest. In this network, $N^{\prime}, A^{\prime}$ represent the total nodes and arcs, respectively, but, in fact, the network is typically large and it is not necessary to take all the nodes and arcs into consideration. Thus, we use $N, A$ to represent the nodes, arcs which are used in the process of evacuation and divide the set of nodes $N$ into three subsets: $N_{k}$ as evacuation zone nodes, $N_{d}$ as evacuation shelter nodes and $N_{o}$ as intersections of evacuation routes. Other parameters and indices are explained in Table 1.

Table 1. Definition of indices, input parameters and decision variables in the model.

\begin{tabular}{|c|c|}
\hline \multicolumn{2}{|c|}{ Indices } \\
\hline$i$ & index for type of evacuees \\
\hline$j$ & index for source type of warnings \\
\hline$t$ & index for time period \\
\hline$k$ & index for evacuation zone \\
\hline$d$ & index for destination shelter \\
\hline$a$ & index for arcs \\
\hline \multicolumn{2}{|c|}{ Notation } \\
\hline$I$ & set of evacuee types \\
\hline$J$ & set of combination types of warning source \\
\hline$T$ & set of time intervals \\
\hline$N_{k}$ & set of evacuation zone nodes \\
\hline$N_{d}$ & set of evacuation shelter nodes \\
\hline$N_{o}$ & set of intersections of evacuation routes \\
\hline$A$ & set of arcs in traffic network used in the evacuation process \\
\hline$\beta$ & percentage of self-evacuate people who evacuate to shelters \\
\hline$Q_{i d}$ & capacity of evacuation shelter $d$ for the evacuees of type $i$ \\
\hline$r_{k d}$ & travel time from zone $k$ to shelter $d$ \\
\hline$n_{i k 1}$ & number of evacuees of type $i$ in evacuation zone $k$ at beginning (time period 1 ) \\
\hline$p_{i j t}$ & evacuation response rate of type $i$ evacuees who received warning from source $j$ at time $t$ \\
\hline$C_{a}$ & capacity of link $a$ in travel network \\
\hline$B_{a t}$ & background traffic of link $a$ at time $t$ in travel network \\
\hline$R_{t}$ & capacity of public transportation at time period $t$ \\
\hline$\delta_{a k}$ & $\{1, \quad$ if link $a$ is used by the evacuees from zone $k$ \\
\hline$o_{a k}$ & 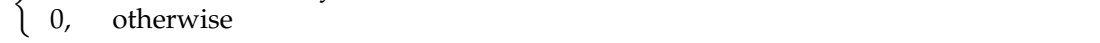 \\
\hline \multicolumn{2}{|c|}{ Decision Variables } \\
\hline & $\int 1, \quad$ if evacuees of type $i$ in zone $k$ are assigned to shelter $d$ \\
\hline$w_{i k d}$ & $\begin{cases}0, & \text { otherwise }\end{cases}$ \\
\hline$x_{i j k t}$ & $\{1$, if a message is sent to type $i$ evacuees from source $j$ in zone $k$ at time $t$ \\
\hline${ }^{*}$ ijkt & $\begin{cases}0, & \text { otherwise }\end{cases}$ \\
\hline$n_{i k t}$ & number of evacuees of type $i$ in evacuation zone $k$ at time period $t, t \geq 2$ \\
\hline
\end{tabular}

\subsection{Objective and Process}

This research aims to optimize warning messages from different sources to specific types of evacuees prior to a hurricane landfall. Warning optimization is a key component of an evacuation plan, allowing management of congestion and proper utilization of evacuation resources like public transportation. The following process is suggested:

1. Identification of danger zones: Identification of risky areas that need to be evacuated depends on the severity of hurricanes. Division of the risky area into geographic zones, and census tract boundaries are used in this study, as this facilitates the generation of population information. 
Location of evacuation zone nodes according to the size and location of the tracts is accomplished using zone centroids.

2. Identification of evacuation routes: After locating the evacuation zone nodes and shelter nodes, we need to determine the routes that evacuees could take. We assume that all evacuees who evacuate by themselves would like to evacuate using the shortest path. Thus, we calculate the shortest paths from each evacuation zone to each shelter by using Dijkstra's algorithm. However, we note that if more information on realistic route choice decisions are available, this can be used to define $\delta_{a k}$.

3. Assignment to shelters: Usually, government agencies set up shelters that are safety areas in response to a hurricane. Considering the capacity of each evacuation shelter, it is typically impossible to accommodate all the people if all evacuees choose the nearest destination. We use a shelter allocation model to assign evacuees from different zones to specific shelters, so as to minimize the total evacuation distance without exceeding the capacity of each shelter. Moreover, when we decide which shelter to use, the route to the destination is determined $\left(\delta_{a k}\right)$ due to the assumption of choosing the shortest path.

4. Evacuation warning optimization: After the above steps, all the input data of our hurricane evacuation warning model are obtained. This model maximizes the total number of evacuees by controlling the spread of warning messages. Its output is an evacuation warning schedule, which provides government decision-maker specific suggestions of spreading warning messages.

\subsection{Mathematical Models}

3.3.1. Shelter Allocation

$$
\text { Min } \quad Z=\sum_{k \in K} \sum_{d \in D} r_{k d} w_{1 k d}
$$

Subject to:

$$
\begin{array}{cr}
\sum_{k \in K} w_{1 k d} n_{1 k 1} \beta \leq Q_{1 d} & \forall d \in D, \\
\sum_{d \in D} w_{1 k d}=1 & \forall k \in K, \\
w_{1 k d} \in\{0,1\} & \forall d \in D, \quad \forall k \in K .
\end{array}
$$

The objective in (1) states that the total travel time from all the evacuation zones to shelters is to be minimized. Constraint (2) makes sure that the number of people who choose to evacuate by themselves to each assigned shelter is no more than the shelter's capacity for private transport. Constraint (3) makes sure that each evacuation zone is assigned to one shelter. Constraint (4) defines the decision variables as being binary.

The main purpose of this model is to find out the destination of self-evacuation and then identify the corresponding shortest paths in the transportation network. Thus, we only take private transport into consideration for shelter allocation. For the public transit part, we use another model [23] to assign shelters and generate subnetworks for public evacuation route in the case study (Section 4.2.4).

\subsubsection{Hurricane Evacuation Warning}

$$
\operatorname{Max} \quad Z=\sum_{i \in I} \sum_{j \in J} \sum_{k \in K} \sum_{t \in T} n_{i k t} p_{i j t} x_{i j k t},
$$


Subject to

$$
\begin{array}{cc}
\sum_{j \in J} \sum_{k \in K} n_{1 k t} p_{1 j t} x_{1 j k t} \delta_{a k} \leq C_{a}-B_{a t} & \forall a \in A, \forall t \in T, \\
\sum_{j \in J} \sum_{k \in K} n_{2 k t} p_{2 j t} x_{2 j k t} \leq R_{t} & \forall t \in T, \\
n_{i k, t+1}=n_{i k t}-\sum_{j \in J} n_{i k t} p_{i j t} x_{i j k t} & \forall i \in I, \forall k \in K, \forall t \in T, \\
\sum_{j \in J} x_{i j k t} \leq 1 & \forall i \in I, \forall k \in K, \forall t \in T, \\
x_{i j k t} \in\{0,1\} & \forall i \in I, \forall j \in J, \forall k \in K, \forall t \in T .
\end{array}
$$

The objective in (5) is to maximize the total number of evacuees at the end of evacuation time period $T$. Constraint (6) makes sure that the number of people who evacuate by themselves that use each link is no more than its capacity. Constraint (7) makes sure that the public transport capacity at each evacuation time period is enough for the people who evacuate by public buses. Constraint (8) calculates the number of evacuees of type $i$ in zone $k$ at the next evacuation time period; this is the number of the evacuees of type $i$ in zone $k$ who remain. Constraint (9) ensures that, in each time period, there is no more than one way to send the warning messages to the particular type of people in one zone because each way $(j)$ represents different possible combination of warning sources. Constraint set (10) defines the decision variables as being binary.

In this model, we take network capacity into consideration as indicated in Constraint (6) in order to minimize the impact of congestion during an evacuation. However, there are also many other factors that could cause congestion in reality. It is noted that the problem of evacuation congestion has been widely studied in the field of transportation research [2,71,72]. We use a simple constraint method for congestion control. Constraint (6) takes background traffic into consideration when we calculate the road capacity, which refers to vehicles in the network that do not belong to evacuation traffic. It is often estimated as a percentage of normal trip tables or a modification thereof [13]. Background traffic includes typical day commuting trips of people who have not received evacuation warnings, trips made in preparation for evacuation such as gathering family members, trips made to gather supplies by those who do not intend to evacuate, and trips made by those evacuating from their homes passing by this region.

In our case study (Section 4), we make the assumption that people choose the shortest paths to assigned shelters or other places near the shelters as the evacuation destinations. Therefore, evacuation routes of self-evacuation are obtained after solving the Shelter Allocation Model, which is an $\operatorname{input}\left(\delta_{a k}\right)$ to the Hurricane Evacuation Warning Model, as indicated by Section 3.2. Nevertheless, it is well-known that evacuees would like to evacuate to hotels, friends/relatives' homes and other places, not just the assigned shelters. Furthermore, the shortest paths can also be replaced by other routes. Thus, when this model is applied to practice, besides choosing shelters as destinations (consistent with $\beta$ in Shelter Allocation Model), the deformation of constraints (6) can further accommodate traffic that travels to hotels or other places by adding known traffic. In addition to this, $\delta_{a k}$ can also be updated if we had more information than just assuming the shortest path.

We note that $n_{i k 1}$ is known, but $n_{i k t}, t \geq 2$ is a decision variable. Therefore, $(P)$ is nonlinear (e.g., see the objective function (5) and constraints (6)-(8)). Due to these nonlinearities, $(P)$ cannot be solved using a solver like CPLEX. To obtain a heuristic solution for $(P)$, we employ an iterative procedure, which works as follows. We start by determining $x_{i j k 1}$ values by solving the following problem: 
$\left(P_{1}\right) \quad$ Max $\quad Z_{1}=\sum_{i \in I} \sum_{j \in J} \sum_{k \in K} n_{i k 1} p_{i j 1} x_{i j k 1}$

Subject to

$$
\begin{gathered}
\sum_{j \in J} \sum_{k \in K} n_{1 k 1} p_{1 j 1} x_{1 j k 1} \delta_{a k} \leq C_{a}-B_{a 1} \quad \forall a \in A, \\
\sum_{j \in J} \sum_{k \in K} n_{2 k 1} p_{2 j 1} x_{2 j k 1} \leq R_{1}, \\
\sum_{j \in J} x_{i j k 1} \leq 1 \quad \forall i \in I, \forall k \in K, \\
x_{i j k 1} \in\{0,1\} \quad \forall i \in I, \forall j \in J, \forall k \in K .
\end{gathered}
$$

Then, we use the values of $x_{i j k 1}$ variables to obtain

$$
\widehat{n_{i k 2}}=n_{i k 1}-\sum_{j \in J} n_{i k 1} p_{i j 1} \widehat{x_{i j k 1}} \quad \forall i \in I, \forall k \in K,
$$

where $\widehat{x_{i j k 1}}$ is the optimal solution for time period 1 from the iterative procedure. We use ${ }^{-}$for values updated from the iterative procedure including $\widehat{n_{i k 2}}$, the remaining population at zone $k$ at time 2. After this, we repeat the process $T$ times, successively obtaining $\widehat{x_{i j k 1}}, \widehat{x_{i j k 2}}, \ldots, \widehat{x_{i j k T}}$ values and the corresponding $\widehat{n_{i k 1}}, \widehat{n_{i k 2}}, \ldots, \widehat{n_{i k T}}$ values. The problem $\left(P_{1}\right)$ and the successive problems $\left(P_{2}\right),\left(P_{3}\right), \ldots,\left(P_{T}\right)$ are linear and can be solved using a commercial MIP solver like Gurobi Optimizer.

It should be noted that there is no guarantee that the solution obtained using this iterative scheme is optimal to $(P)$. We argue, however, that the iterative procedure provides close-to-optimal solutions through the cases in Appendixes A and B. In the first case (Appendix A), we demonstrate that the iterative scheme method could get the optimal solution if there is a single type of evacuee in the single zone. In the second case (Appendix B), when there are multiple zones, we find a counterexample that shows our scheme is not the optimal. However, this situation is one of "exceptional cases" and there are few such cases under the practical condition. For example, for multiple zones (share the same links) evacuating in two time periods, this situation happening should meet at least the following two conditions: (1) the maximum number of evacuees of iterative scheme solution in the last time period is much less than the capacity and the gap is large enough; (2) the response rate of the last time period is much higher than the first time period. In reality, these two conditions are very unlikely.

\subsection{Discussion}

We developed and tested a simulated annealing heuristic to improve the solution obtained from the iterative heuristic. Despite extensive attempts, we were not able to use simulated annealing to improve the solution obtained by the iterative heuristic. This indicates that our iterative scheme method may have already found a near-optimal solution, as indicated by the result in Appendix A.

The Hurricane Evacuation Warning Model is a multi-period model, which organizes the release of warnings. When using the sequential logit model to estimate dynamic travel demand, the decision to evacuate is considered as a series of binary choices over time [53]. Thus, as the government sends warnings strategically over time, it makes an impact on the evacuation decision. Even though not all the people would comply with the warnings, the response rate for evacuation in a certain time period is affected by the warnings source, and also the time period (time pressure) and the type of people receiving the warnings.

There could be any interactions across periods, leading to $p_{i j t}$ values changing as the evacuation process evolves. For example, as the number of non-evacuated individuals in a zone declines, this zone would tend to have a lower response rate. Thus, the $p_{i j t}$ of a zone might be expressed by the function 
of $f\left(\sum_{j \in J} x_{i j k t-1} p_{i j t-1}, S_{i j k t}\right)$. Here, we define $S_{i j k t}=1$ if an evacuation warning has been issued before time period $t$, and 0 otherwise.

One advantage of our iterative scheme method is its ability to change parameters after each iteration. When we run the model, we calculate the remaining people of each time period as an input to the next period, and this gives us an interface to recalculate the $p_{i j t}$ based on the actual situation that happened in order to get more realistic evacuation demand. Moreover, the capacity of links $\left(C_{a}\right)$ can also be modified after each iteration. The case where $p_{i j t}$ values are changed to reflect response in prior periods is tested in the case study (Section 4.2.2).

\section{Case Study}

For this study, Brooklyn (Kings County) in New York was chosen to be analyzed under the backdrop of Hurricane Sandy. A hurricane evacuation warning schedule is generated as an outcome of our model. To establish a point of comparison, we conduct another experiment that sends evacuation warnings from all the sources together for each time interval. We also discuss the integration of public transit into the evacuation planning approach.

\subsection{Data Collection}

\subsubsection{Traffic Evacuation Zones and Shelter Locations}

NYC Emergency Management plans and prepares for emergencies, educates the public about preparedness, coordinates emergency response and recovery, and also collects and disseminates emergency information. New York City's hurricane contingency plans are based on six evacuation zones that are color-coded. Figure 1 shows the evacuation area with different color labels for Brooklyn; the red zones are the most affected zones.

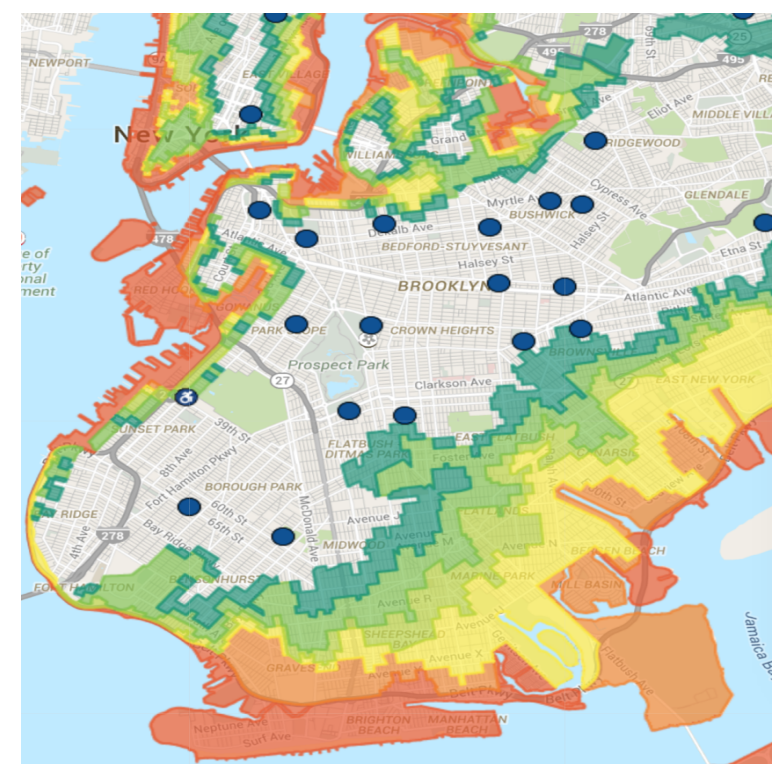

Figure 1. Brooklyn evacuation zones and shelters.

Figure 1 also presents the evacuation centers in Brooklyn, which are labeled by blue points. These locations are the shelters provided by the government and the information of the shelters are available online for the public to prepare in case of an emergency. The capacity of each shelter can be found on the Sandy Facilities list. 


\subsubsection{Other Parameters and Assumptions}

In order to obtain the number of people in evacuation zones and also the traffic network information, Quantum GIS (QGIS) is used for visualization of shapefiles (geospatial vector data format) and gathering of the information together.

Firstly, the underlying road network of Brooklyn has been taken from the metropolitan planning organization, New York Metropolitan Transportation Council (NYMTC). In addition, the shape file is created in QGIS, which includs basic information of the network such as the path distance, direction, and number of lanes. Secondly, the shapefiles of Brooklyn Census Track dataset which join the geometry and selected attributes from the 2010 Census TIGER/Line Shapefiles and the 2010 Census Summary Demographic Profile are added in QGIS. In addition, according to the Figure 1, the evacuation area is divided by tracts as separate evacuation zones and all the zones and shelters are located on the map shown as Figure 2. Based on the evacuation zones (tracts) information, the evacuation zone nodes are also located as the aggregate demand points. These nodes and underlying network are all displayed in Figure 2.

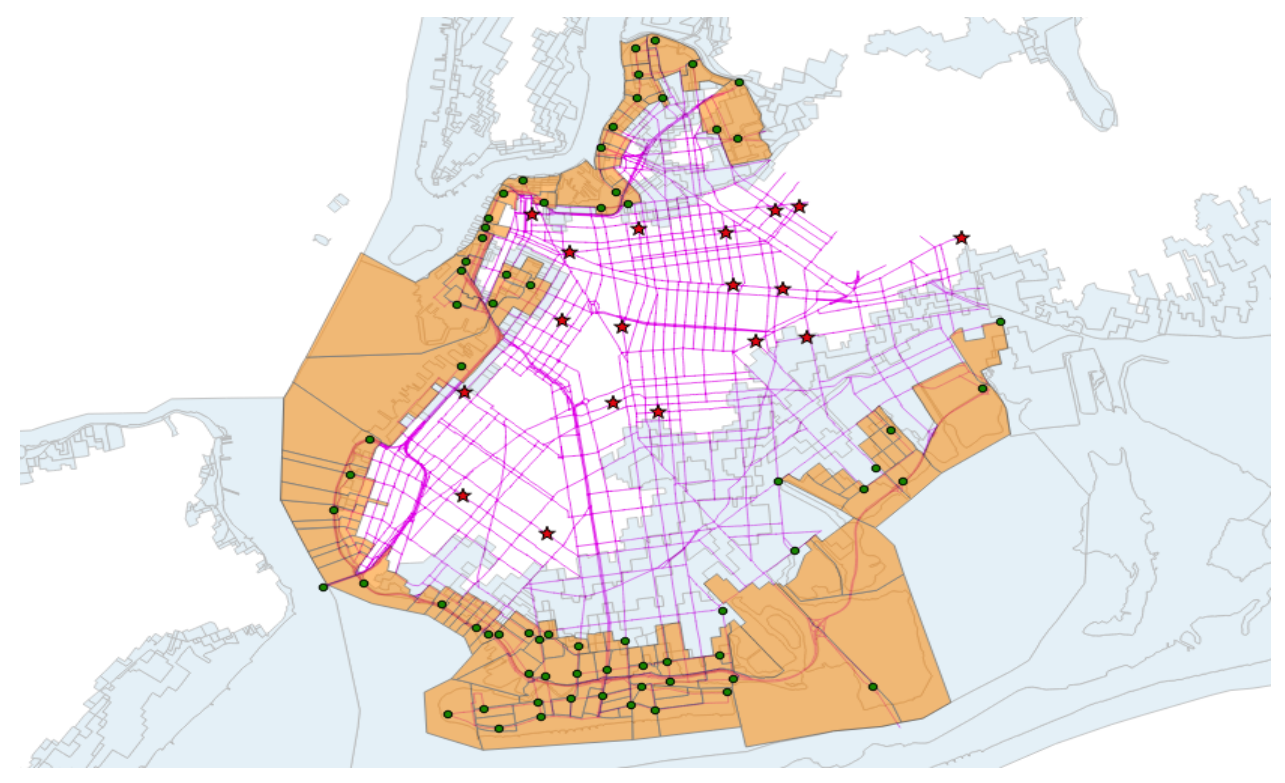

Figure 2. Brooklyn underlying network.

The second step of our approach is to determine possible evacuation routes. Movement occurs from each evacuation zone node to each possible shelter using the underlying network. Travel time of each path is calculated first by using the path distance divided by the average vehicle speed on that path. Then, Dijkstra's algorithm is used to find the shortest path from each zone to each shelter and a shortest travel time matrix is generated, which is an input data $\left(r_{k d}\right)$ to the Shelter Allocation Model. After solving the Shelter Allocation Model, the links $(a)$ used for each zone $(k)$ are identified $\left(\delta_{a k}\right)$, as an input to the Hurricane Evacuation Warning Model. It is noted that, for odd-shaped zones (e.g., west bank of Brooklyn), we can get unrealistic shortest path and allocation matrices.

Other inputs of the models are illustrated as follows:

$$
\text { Time interval (T): } 3 \mathrm{~h} / \text { interval (36 h), } T=12 \text {. }
$$

Number of different types of evacuees $\left(n_{i k t}\right)$ : Considering the percentage of car-free households $(56 \%)$ in New York City, we make the assumption that $44 \%$ of people evacuate by themselves $(i=1)$ and $56 \%$ of people evacuate by public transportation $(i=2)$.

Percentage of people assigned to shelters $(\beta)$ : Not all people prefer to evacuate to shelters. In fact, most evacuees like hotels and relatives' houses. A study predicted that averages about 
$15 \%$ of evacuated population use shelters in the United States by using behavioral survey data [73]. Thus, in this case study, we assume that $15 \%$ of people evacuated by themselves and assign them to the corresponding shelter $(\beta=15 \%)$. Actually, $\beta$ might be less than that according to research reported [74], but we take the worst situation into account in order to make sure that all the shelters could accommodate assigned people.

The evacuation response rate after receiving a specific warning $\left(p_{i j t}\right)$ : This parameter is calculated based on evacuation behavior research and is an input from the social science field. Since it is not a key object of this research to determine accurate $p_{i j t}$ values, we assume that values of this parameter can be calculated based on relevant references in the social science field [53]. The fixed input numbers are set subject to these rules: (a) people who evacuate by themselves are more likely to evacuate by public transportation; (b) people would like to evacuate after receiving information from an official source, followed by NWS, media, friends and relatives. This means an evacuate decision is made based on different information sources to varying degrees; (c) just as normal daily trips, people usually choose to evacuate in the daytime rather than by night; (d) people make the decision of evacuation follows some rules about the time before a hurricane landfall, and the cumulative departure usually follows an S-curve. Based on the above, along with the practical situation of evacuation under the scenario of a hurricane, we assume knowledge of the $p_{i j t}$ parameters (Appendix C).

Capacity and Background Traffic: The capacity of a road is 2400 vehicles per hour per lane for a freeway and 1800 vehicles per hour per lane for urban roads [75]. Since there is limited information about the amount of background traffic that would be present during an evacuation, approximations of background traffic are used based on recorded daily traffic volumes [76]. A uniform distribution is assumed for the rate of decline of the background traffic. This study calculates background traffic as a percentage of normal trip tables, which declines as the evacuation occurs and decreases to zero. We use the Hourly Traffic Data, which is the percentage of AADT (Annual Average Daily Traffic) occurring in each hour of the day, to generate normal daily trips data of Kings county (Brooklyn). According to the study, which makes the hourly distribution translate into sound levels using statistical data [77], we employ an hourly traffic volume distribution table, and the AADT data of Brooklyn, which is obtained from New York State Department of Transportation (NYSDOT), to generate normal trip tables. Due to the uniform distribution for the rate of decline of the background traffic, the background traffic volume also could be calculated for each time interval. It is to be noted that, when we calculate the capacity of each link, we assume two persons as the average number in each vehicle, so as to convert the capacity unit as persons per link.

\subsection{Analysis of Results}

\subsubsection{Computational Results}

We use the Brooklyn data to show the computational performance of our model. Given the initial number of people in each evacuation zone, we solve the Shelter Allocation Model and optimize the warning messages in the first evacuation time period using the Gurobi Optimizer (mathematical programming solver), and then compute the evacuate number to calculate the next time period of people who did not evacuate. At last, we use the iterative scheme outlined to determine the optimal warnings for each time period.

Figure 3 shows the zones needed to send specific types of warnings at different time intervals. As shown in Figure 3a, in the zones colored green, we do not send any evacuation messages in the first time period in order to avoid congestion, and almost all the other zones, except zones 64 and 65, where we send warning messages from all the sources. From Figure $3 b$, we see that there are more zones that need to send no warning at time period 2. In addition, what should be noted is that at time intervals 8 and 9 , there are more warning source types that need to be used to improve evacuation efficiency, and all the used warning types in the solution are labeled in Figure 3. 


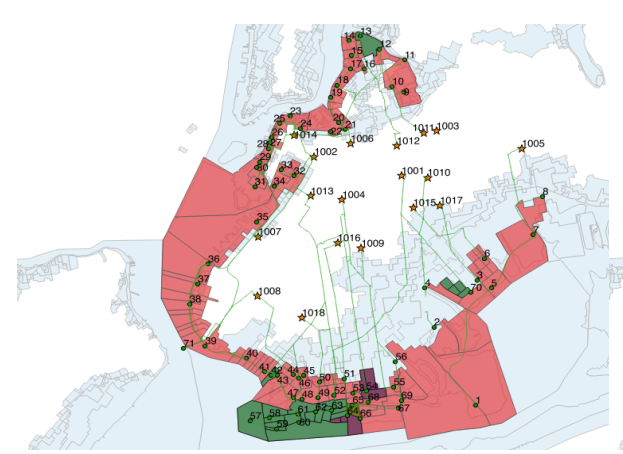

(a)

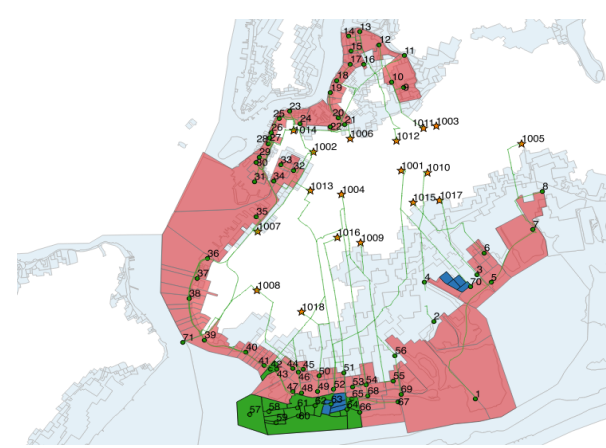

(c)

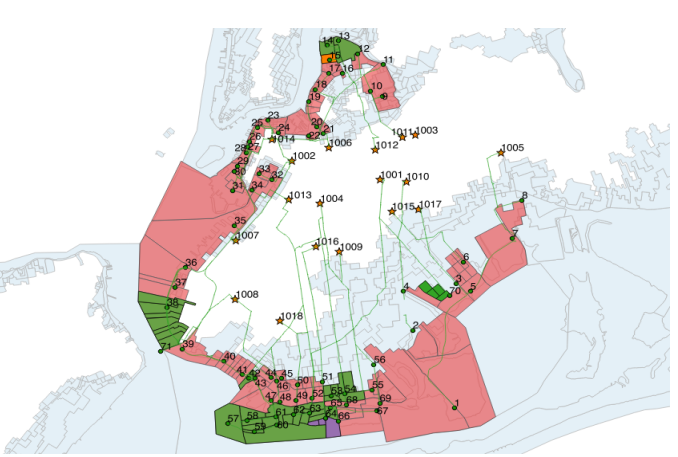

(b)

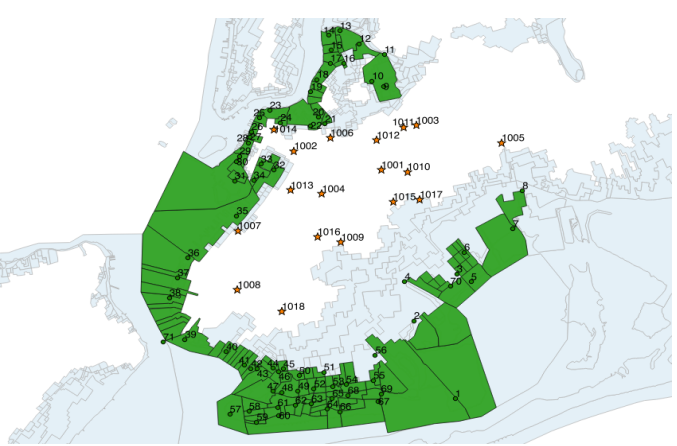

(d)

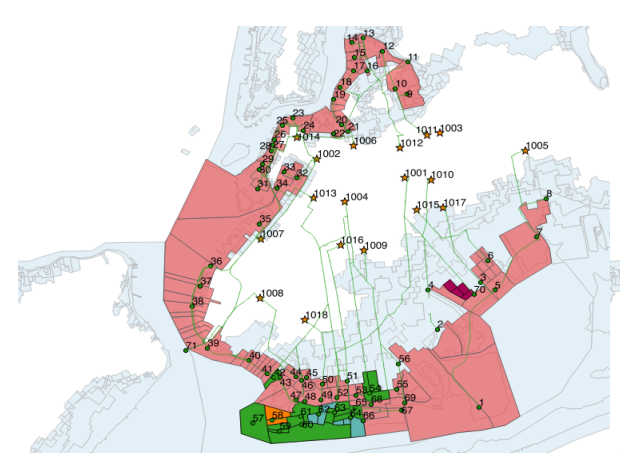

(e)

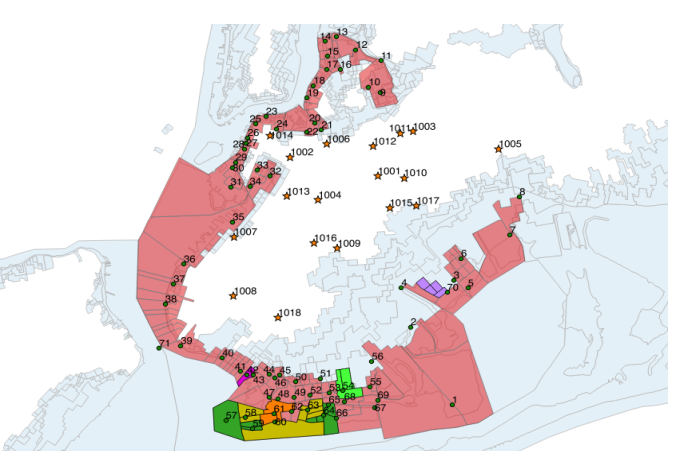

(f)

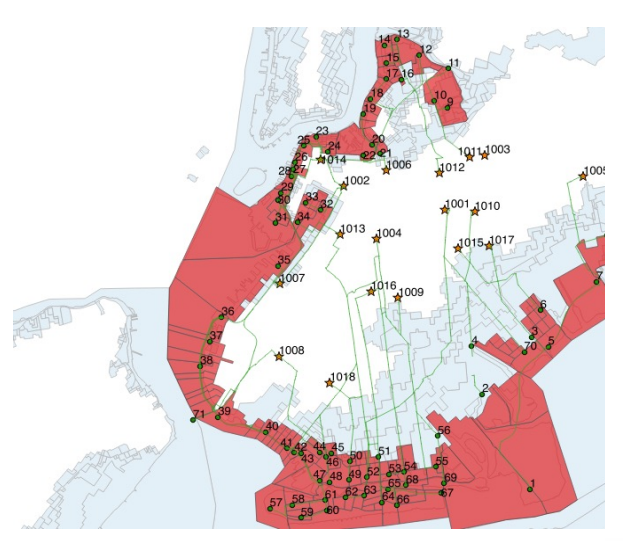

(g)

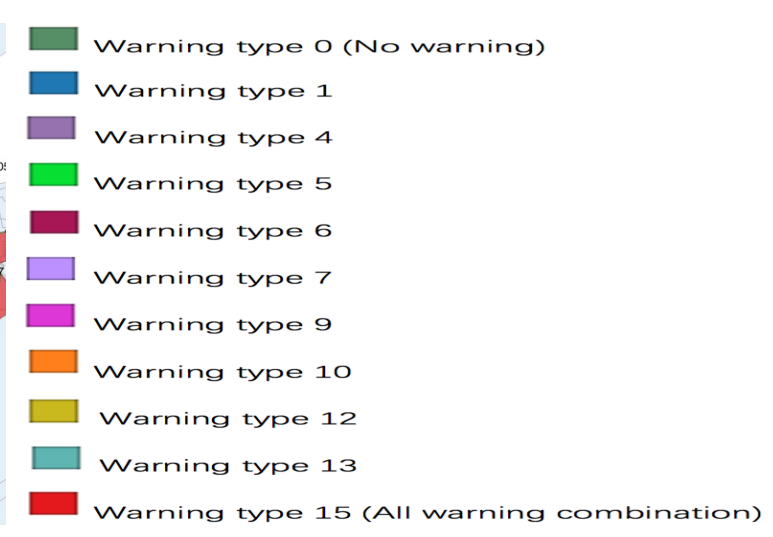

(h)

Figure 3. Evacuation warning schedule map. (a) evacuation warning map at time $1 ;$ (b) evacuation warning map at time 2; (c) evacuation warning map at time 3; (d) evacuation warning map at times 5, 6; (e) evacuation warning map at time 8; (f) evacuation warning map at time 9; (g) evacuation warning map at other times; (h) color indicator. 
The table in Appendix D is the warning schedule of the Brooklyn area during a hurricane of Category 1 . The zone column represents the tracts that are needed to evacuate Brooklyn, and are divided into 71 zones. The other columns are the warning source types at the corresponding time intervals. In this case, $j=0$ means sending no evacuation messages to this zone; $j=1,2,3,4$ represent sending messages from official, NWS, media, and social network, respectively; $j=5-10$ denote sending messages from two kinds of sources at the same time interval; $j=11-14$ respect for sending messages from three kinds of source combinations; $j=15$ sends messages from all the sources together (Table 2).

Table 2. Definition of warning type.

\begin{tabular}{cl}
\hline Warning Source $j$ & Source Type \\
\hline$j=0$ & sending no evacuation messages \\
$j=1$ & official \\
$j=2$ & National Weather Service (NWS) \\
$j=3$ & media \\
$j=4$ & social network \\
$j=5-10$ & sending messages from two kinds of sources \\
& which denotes official \& NWS $(1$ \& $), 1$ \& $3,1 \& 4,2 \& 3,2 \& 4,3$ \& 4 respectively \\
$j=11-14$ & sending messages from three kinds of source combination \\
& which denotes 1 \& 2 \& $3,1 \& 2 \& 4,1 \& 3$ \& $4,2 \& 3 \& 4$ respectively \\
$j=15$ & sending messages from all the sources together $(1 \& 2 \& 3$ \& 4$)$ \\
\hline
\end{tabular}

In the result shown (Appendix D), at times 5 and 6, there are no evacuation warnings. This is because we set 12:00 p.m. as the beginning of the evacuation period and thus time intervals 5 and 6 refer to 12:00-6:00 a.m. in this case, and we assume that there are no warnings during the night. At time intervals 10-12, there are not so many people needed to evacuate compared to the road capacity. Therefore, all the warning source combinations should be used to evacuate more people.

In this experiment, there are 413,302 people living in the evacuation zones at the beginning, and 393,742 people who evacuate at the end. This is a $95 \%$ evacuation rate.

\subsubsection{Adjustment of Response Rate}

Our iterative scheme makes it possible to adjust $p_{i j t}$ at each time period, no matter how it changes, and even make it specific to distinguish zones as $p_{i j k t}$ if it is necessary. Based on the previous case, we make some adjustments of parameter $p_{i j t}$, in order to show the procedure of our method, which changes the input parameters over time. The examples are as follows:

Example 1. The parameter $p_{i j t}$ is sensitive to the time interval, as in this case study. Since people might need more time to prepare for an evacuation, the prior time period warning could lead to an increasing evacuation rate at this time period, which also gives us the insight to conduct an evacuation demand model by considering mobilization time in future work. We illustrated this case as the situation when people receive warnings during the first time period but evacuate during the second time period, thus increasing the $p_{i j 2}$ value.

Example 2. After several time periods, as the number of non-evacuated individuals declines, the $p_{i j t}$ tends to be lower, which means that the utility of warning decreases. We illustrated this case as after time period 7 , and $p_{i j t}$ for $t \geq 7$ is decreased over time.

The following steps are details of $p_{i j t}$ adjustment in our method, and we put these two examples in one experiment:

- Step 0. All the data inputs are the same as the previous case study.

- Step 1. Solve the shelter allocation model and hurricane evacuation model of time period 1 (Model $\left.\left(P_{1}\right)\right)$ by using Gurobi. 
- $\quad$ Step 2. Adjust values of response rate at time period 2 as $\widehat{p_{i j 2}}$. Then, update this parameter $\widehat{p_{i j 2}}$ along with $\widehat{n_{i j k 2}}$ obtained from Model $\left(P_{1}\right)$, input to Model $\left(P_{2}\right)$, and solve the linear problem $\left(P_{2}\right)$.

- Step 3. For time periods 3-6, repeat the iterative procedure with updated $\widehat{n_{i j k t}}$ values by using the solution of the previous time period $\left(\widehat{x_{i j k t-1}}\right)$. Other parameters are the same as the previous case study. Although $\widehat{p_{i j t}}$ during time periods 3-6 are the same as the previous case study, because of the changing of $\widehat{p_{i j 2}}$, the results for time periods $3-6$ are different.

- Step 4. For time periods 7-12, similar to step 2, updated values of $\widehat{p_{i j t}}$ each iteration, in addition to $\widehat{n_{i j k t}}$ values, and then get the result of the whole warning schedule.

The updated numbers of $p_{i j t}$ are shown in Appendix E, and the result of this adjustment are shown in Appendix F. In this case, for 413,302 people living in the evacuation zones, it leads to 382,541 people evacuated at the end. This is a $92 \%$ evacuation rate. Appendixes D and F are the warning schedules with the adjustment of parameter $p_{i j t}$. By contrasting these two strategies, we found that when the $p_{i j 2}$ increase (Example 1), the warning sending solution needs to change in the zones 4, 15, 19, 64, 65 at time period 2 and also affects the strategies of the next period. As $p_{i j t}$ changes in the last several time intervals (Example 2), it mainly affects the strategies of time periods 8 and 9 in zones 55-65 because these zones' evacuation routes share capacity of the same roads. In the last three time periods, the effect of the warning is so minor that most of the people who decided to evacuate have already left. It should be noted that we could also use this procedure to change the capacity of links if many two-way roads were turned into one-way roads heading away from the coast according to the actual circumstance.

\subsubsection{Result Comparison}

Figure 3 shows the evacuation warning schedule that gives us different warning sending strategies with the change of time period. We conduct another experiment to compare with the situation when all the warnings are sent to each zone in each time period.

In the second experiment, all of the data are as the same as the first one. We only change the warning sending strategy by sending all warnings together at each time period. In this case, people attempt to evacuate at the same time, which raises the demand of evacuation in all risky zones. However, it is infeasible to apply this solution to our model, due to road capacity violation. Figure 4 is the traffic network of evacuation in Brooklyn at the first and second time periods, and it shows blocked roads (colored by red) when we send all evacuation warnings. In this case, we can not evacuate all the people who want to evacuate. On the contrary, the evacuated cars could be stuck on the road and this reduces the evacuation efficiency.

If we assume that all the people can be evacuated in time regardless of the road capacity, we can send all the warnings together at each time period in order to evacuate as many people as we can. Then, the evacuation rate is observed as shown in Figure 5b. In Figure 5, private lanes refer to the use of the shoulder and center turning lanes for regular traffic, whereon public lanes refer to the use to regularly usable lanes. Compared with the evacuation rate of the first experiment, which is the result of optimal warning sending solution (Figure 5a), the evacuation rate of all warning increases faster in every time period except time periods 5 and 6 , and almost all the people evacuated before time period 10. However, in reality, it is impossible to respond to the maximum demand of evacuation like Figure $5 \mathrm{~b}$ shows because of the limitation of road capacity. As is shown in Figure $4 a$, at the beginning of evacuation, there has already been traffic congestion in some links. Moreover, in the next time period, another large amount of cars join for evacuation, causing further congestion. Thus, it would definitely delay the evacuation process if all warnings are sent in each time period, since avoiding traffic congestion is an essential prerequisite for improving the efficiency of evacuation. Figure $5 \mathrm{a}$ shows the evacuation rate of the first experiment, which gives the optimal solution of sending warnings in order to avoid congestion, and it is likely the highest achievable evacuation rate in actual conditions which take road capacity into consideration. 


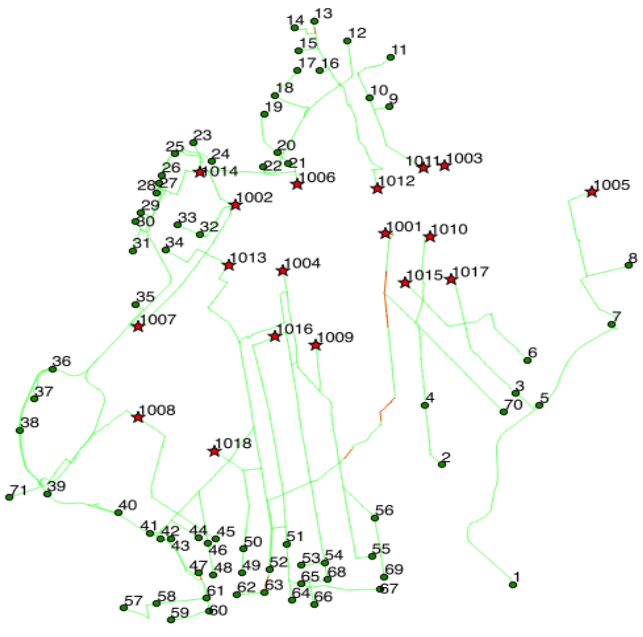

(a)

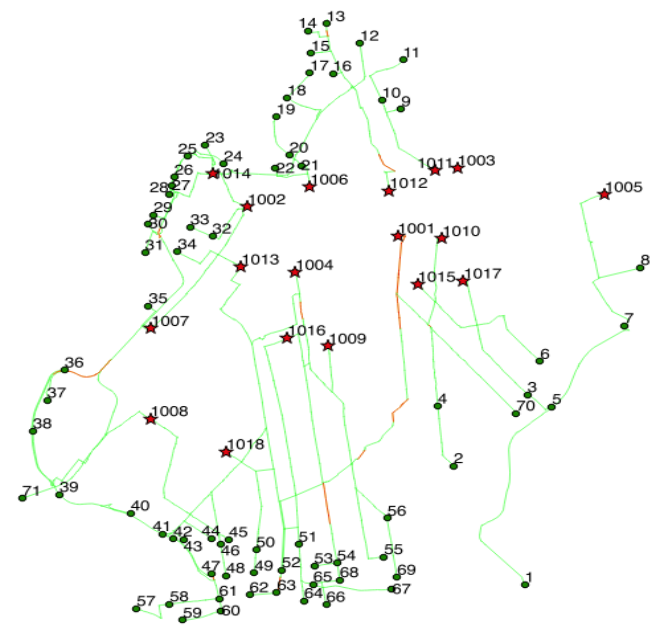

(b)

Figure 4. Congestion of all warnings. (a) congestion at time 1 ; (b) congestion at time 2.

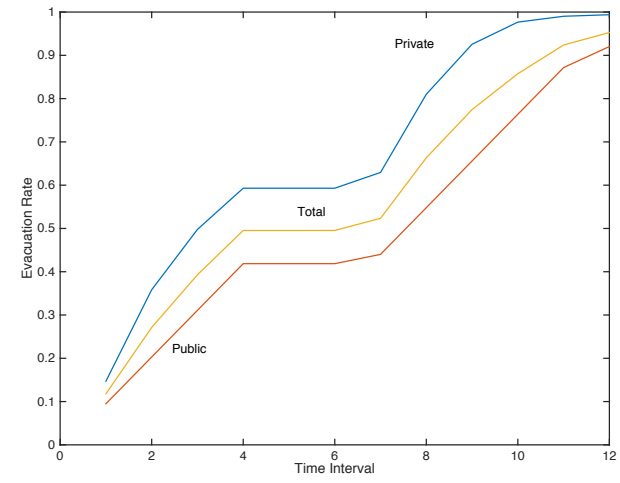

(a)

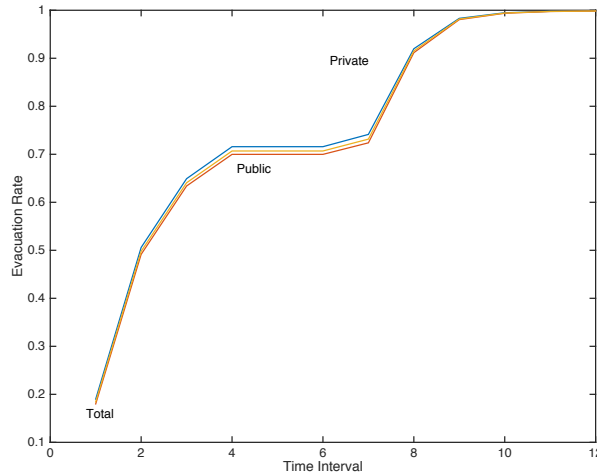

(b)

Figure 5. Evacuation rate. (a) evacuation rate-optimal; (b) evacuation rate-all warnings.

In order to view the distance effect on the optimal result, we classify the zones into three categories. Zone 1 are the zones farthest from shelters, Zone 3 represents the nearest zones, and Zone 2 are the zones in the middle. According to the Figure 6, the distance between the evacuation zone and shelter has a notable effect on evacuation planning by analysis of the result of our optimal warning solution.

The most obvious difference between the nearest zones and farthest zones is that the closer evacuation zones are from shelters, the faster the evacuation rate goes up, which is clearly shown in Figure $6 a, c$. It means that, in the optimal solution, in order to evacuate as many people as we can, it is necessary to evacuate the nearest zones before the farther zones, and Figure $6 \mathrm{~d}$ shows the contrast of total evacuation rate in different zones clearly.

\subsubsection{Evacuate by Public Transit}

For public transportation, we used a multi-stage approach presented by Swamy et al. [23] in this paper. In their approach, they first use a Set cover model to obtain a set of pickup locations, then run a Shelter assignment model to create the subnetworks that are the input to the Initial-route generation model, and employ a Simulation model to reproduce a real world environment. In our case study (experiment 1), we generated a warning schedule for both self-evacuation and car-less population, thus obtaining the evacuation demand for different population types. However, due to the capacity limitation of public transit, and evacuee-based events such as balk, not all people could be evacuated 
in a real-world environment. Therefore, we extend our case study by using the methodological framework [23] to analyze the real public evacuation rate.

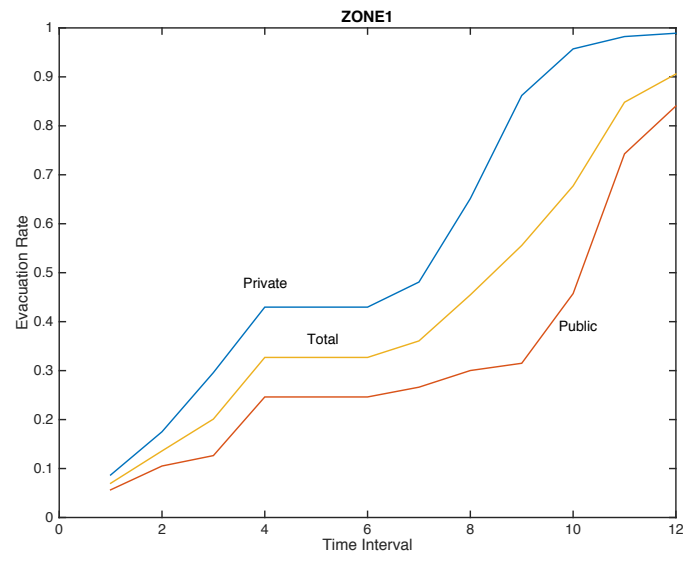

(a)

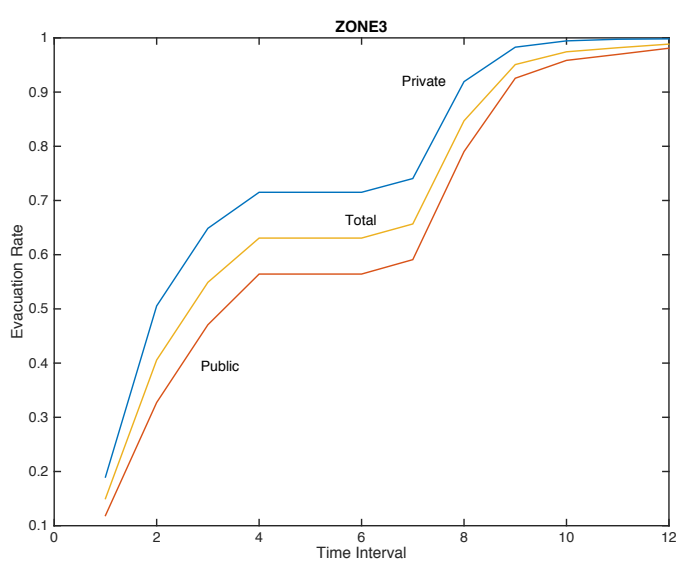

(c)

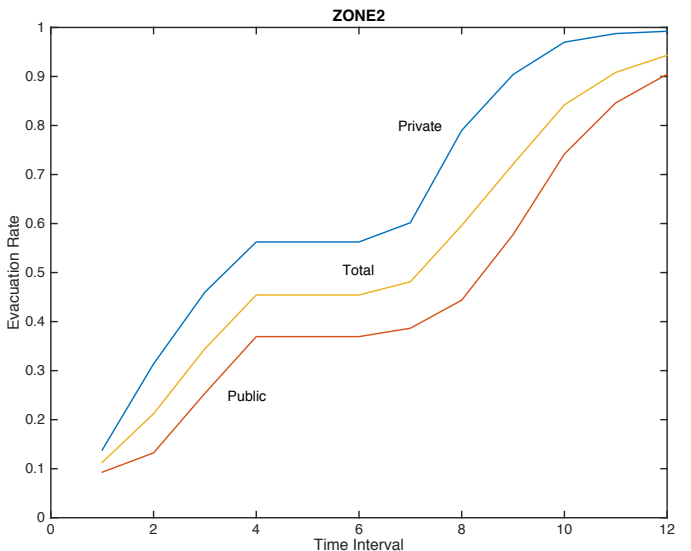

(b)

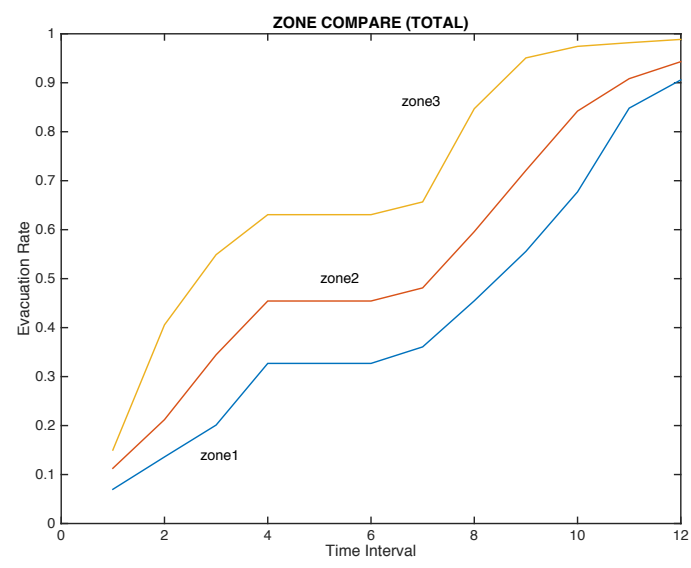

(d)

Figure 6. Evacuation rate of different zones. (a) evacuation rate of the farthest zone 1; (b) evacuation rate of farther zone 2; (c) evacuation rate of nearest zone 3; (d) total evacuation rate comparison.

In the study of public transportation [23], they also analyze the evacuation during Hurricane Sandy in the area of Brooklyn. Since the same database is used in our research, we obtain the same results of the Set cover model, Shelter assignment model, and Initial-route generation model, which act as inputs to the simulation. The chosen bus stops are shown in Figure 7a. Our solution of sending warnings to the people evacuated by public transportation generates a more realistic arrival demand of each pickup location over time. Thus, we do some changes of the simulation parameters as follows:

- Demand arrival time period: $1 \mathrm{~min}$;

- Evacuation period: $36 \mathrm{~h}$, or $2160 \mathrm{~min}$;

- Capacity of a bus: 56;

- Total number of available bus: 100;

- Balk threshold: 56 evacuees;

- $\quad$ Renege threshold: 45 min;

- Percentage of dissatisfied evacuees self-evacuation: $50 \%$;

- Demand: When we apply our model to the Brooklyn region (experiment 1), we obtain the optimal solution for sending evacuation warnings. Based on this warning schedule, the public transportation demand of each time interval in experiment $1(3 \mathrm{~h} /$ period) is calculated, and we 
make an assumption that the demand arrival distribution of each time interval fitted normal distribution in order to get the demand for each time period $(1 \mathrm{~min})$ at each pickup location.

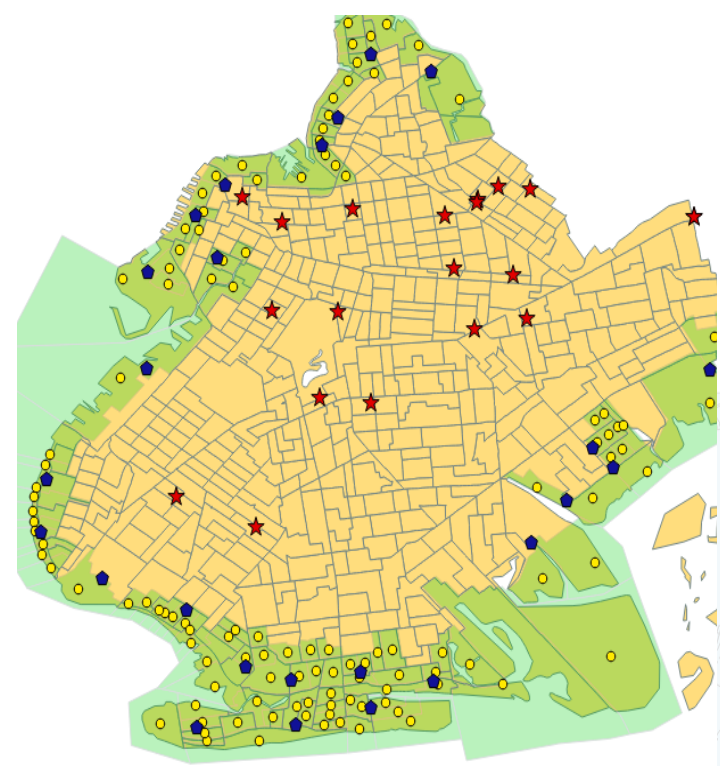

(a)

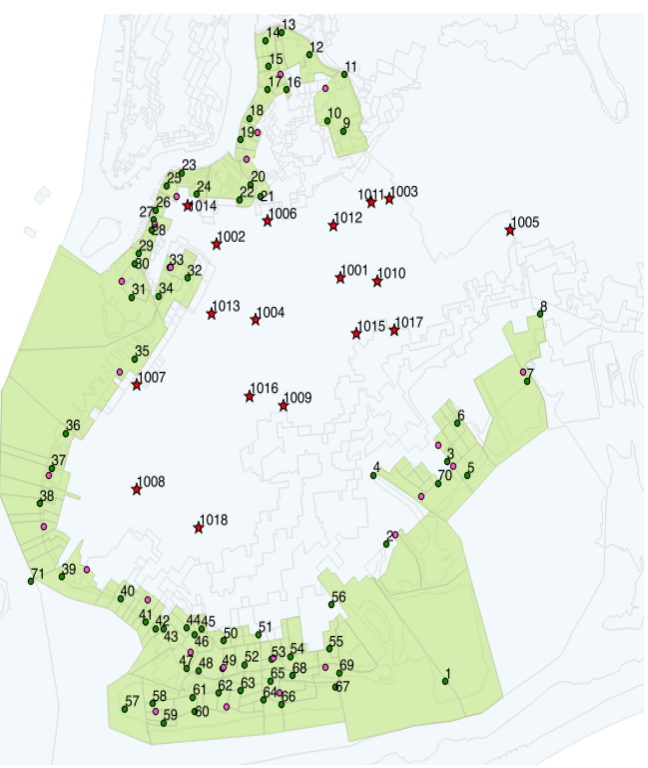

(b)

Figure 7. Bus stops and pick up locations. (a) chosen bus stops; (b) evacuate locations.

In addition, it is necessary to mention the following points as supplements to illustrate the input data. Firstly, all of the areas chosen for analysis are the same as experiment 1, which is the Brooklyn region, so the number of people at each tract is unchanged. However, when we assign the number of people to the pickup location (bus stops), all the people at zone nodes demand are merged to the nearest pickup location except one zone (zone 71) shown in Figure $7 \mathrm{~b}$, which records the number of evacuees coming from Staten Island. The reason we account for the self-evacuation in this zone is that Staten Island is connected to Brooklyn by the bridge, and some of the people living in the part near Brooklyn might want to evacuate to Brooklyn by their own vehicles. However, there are some shelters located on the island, and there is no need for people who evacuate by public transportation to walk to the bus stop in Brooklyn due to the distance.

By using these data as an input to the simulation model, we can obtain the percentage evacuated. Figure 8a shows the comprehensive results of evacuation rate by using this method. As we can see, there is little difference when comparing Figures $5 a$ and $8 a$, which is caused by the difference of public transportation rate. Actually, the public transportation rate curve in Figure $5 \mathrm{a}$ is the demand over time, which means that, when we send the warnings as planned, we get the percentage of people who choose to evacuate instead of staying at home. Figure 8a describes the rate of evacuation, which means the rate of people who have already evacuated by public transportation-it must be lower than the demand rate in Figure 5a.

In order to assist with the decision-making process, we also analyzed the effect of the number of buses used on the evacuation rate. According to the report after Hurricane Sandy, the NYCHA and NYPD (New York Police Department) provided 200 buses to help residents evacuate [42]. Since the buses are used for evacuating all of NYC, we compared the performance of different bus numbers for the Brooklyn region, which included 50,100, and 200. We observe that the evacuation rate grows with the increasing of bus numbers (Figure $8 b$ ). Authorities could assign the buses based on existing public transportation resources in order to satisfy the public evacuation demand. 


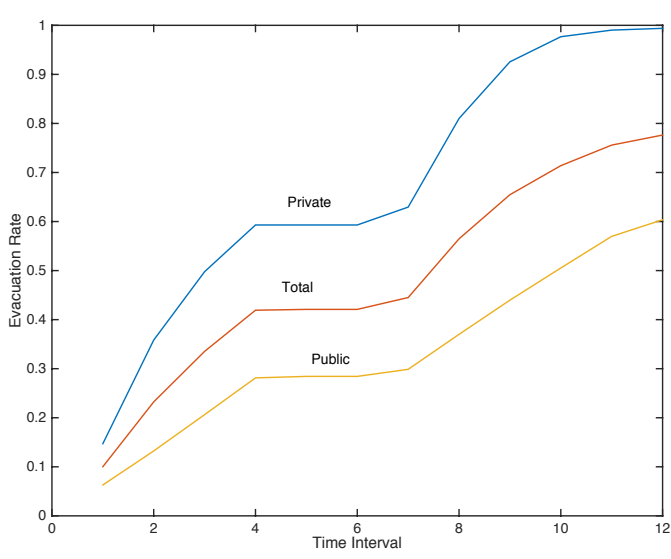

(a)

Figure 8. Result of public transportation. number comparison.

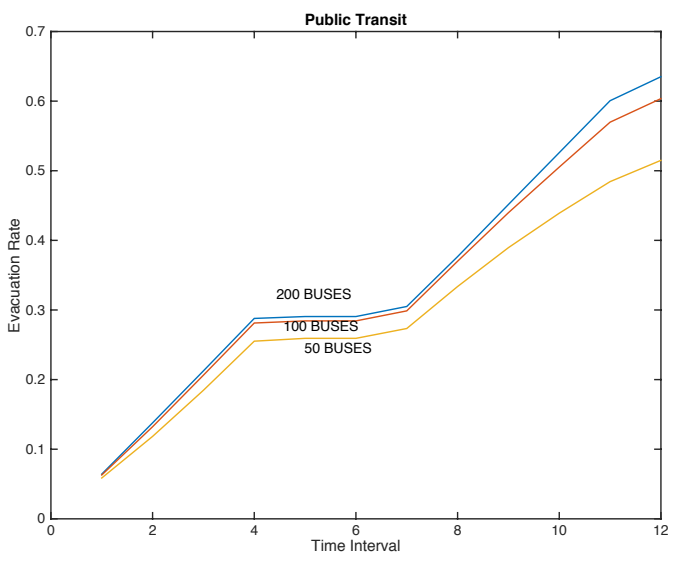

(b)

\section{Conclusions}

In this paper, a modeling framework was presented to deliver warnings for evacuation planning during a hurricane. It reveals that sending warnings judiciously could help evacuation efficiency. The model determines warning sending sources in different time periods during the evacuation process. Both self-evacuation and public transportation evacuation are considered in this methodology. The entire modeling framework has been applied to the Hurricane Sandy scenario in the area of Brooklyn. This case study shows that this methodology generates reasonable and meaningful results, and it could be used for making evacuation planning and also informing the public during an evacuation process. In addition, the modeling framework could easily be transferred to other regions.

Acknowledgments: The study was supported by the Chinese National Nature Science Foundation (Grant No. 71771061) and the Major Strategic Research Plan of Harbin Engineering University (Grant No. HEUCFW170903).

Author Contributions: Dian Sun and Yan Song conceived and designed the research. Jee Yun Kang and Dian Sun analyzed the data. Rajan Batta and Jee Yun Kang contributed analysis tools and study design; Dian Sun carried out the manuscript preparation. Yan Song revised the paper. All authors read and approved the final manuscript.

Conflicts of Interest: The authors declare no conflict of interest.

\section{Abbreviations}

The following abbreviations are used in this manuscript:

$\begin{array}{ll}\text { NYC } & \text { New York City } \\ \text { NDP } & \text { Network Design Problem } \\ \text { NWS } & \text { National Weather Service } \\ \text { NOAA } & \text { National Oceanic and Atmospheric Administration } \\ \text { NYCHA } & \text { New York City Housing Authority } \\ \text { QGIS } & \text { Quantum Geographic Information System } \\ \text { NYMTC } & \text { New York Metropolitan Transportation Council } \\ \text { AADT } & \text { Annual Average Daily Traffic } \\ \text { NYSDOT } & \text { New York State Department of Transportation } \\ \text { NYPD } & \text { New York Police Department }\end{array}$

\section{Appendix A. Optimality of Iterative Procedure for a Single Zone Case}

Consider the simple case of a single evacuation zone and single evacuee type population with two time periods $(T=2)$, and with no road capacity constraint. There are $n_{1}$ evacuees of one single type in period 1 for this single zone. The global objective is to maximize the total number of evacuees 
$\left(Z=Z_{1}+Z_{2}\right)$, while the iterative scheme will maximize the number of evacuees at each time period: $Z_{1}$ in time period 1 , and the $Z_{2}$ in time period 2 . We show that the iterative procedure of evacuating the maximum number of people for each time period leads to maximizing the total number of people:

$$
\operatorname{Max} \quad Z=Z_{1}+Z_{2}=\sum_{j \in J} n_{1} p_{j 1} x_{j 1}+\sum_{j \in J} n_{2} p_{j 2} x_{j 2}
$$

Subject to

$$
\begin{gathered}
\sum_{j \in J} x_{j t} \leq 1 \quad \forall t \in T, \\
x_{j t} \in\{0,1\} \quad \forall j \in J, \forall t \in T, \\
n_{2}=n_{1}-\sum_{j \in J} n_{1} p_{j 1} x_{j 1} .
\end{gathered}
$$

We can define $\widehat{p_{1}}=\sum_{j \in J} p_{j 1} \widehat{x_{j 1}}$, and $\widehat{p_{2}}=\sum_{j \in J} p_{j 2} \widehat{x_{j 2}}$ as the evacuation rate at each time period, where $\widehat{p_{1}} \in(0,1)$, and $\widehat{p_{2}} \in(0,1)$. We obtain

$$
\begin{aligned}
\widehat{Z}=\widehat{Z_{1}}+\widehat{Z_{2}} & =n_{1} \widehat{p_{1}}+n_{2} \widehat{p_{2}} \\
& =n_{1} \widehat{p_{1}}+n_{1}\left(1-\widehat{p_{1}}\right) \widehat{p_{2}} \\
& =n_{1}\left(\widehat{p_{1}}+\widehat{p_{2}}-\widehat{p_{1}} \widehat{p_{2}}\right),
\end{aligned}
$$

where $\widehat{Z_{1}}, \widehat{Z_{2}}$, and $\widehat{Z}$ are the numbers of evacuees in time period 1,2 , and total, respectively.

Letting ${\widehat{p_{1}}}^{\prime}$ and $\widehat{p}_{1}^{\prime \prime}$ be the values of possible $\widehat{p_{1}}$, we verify that, for any ${\widehat{p_{1}}}^{\prime} \geq{\widehat{p_{1}}}^{\prime \prime}$, we have

$$
\widehat{p}_{1}^{\prime}+\widehat{p_{2}}-{\widehat{p_{1}}}^{\prime}{\widehat{p_{2}}}^{\prime}{\widehat{p_{1}}}^{\prime \prime}+\widehat{p_{2}}-{\widehat{p_{1}}}^{\prime \prime} \widehat{p_{2}}
$$

If the above claim is true, for any evacuation rate that is larger than or equal to time period 1 will lead to a larger than or equal to total evacuation rate.

The proof is the following. Reorganizing Equation (A8),

$$
\begin{array}{cr}
\widehat{p}_{1}^{\prime}-\widehat{p}_{1}^{\prime} \widehat{p}_{2} \geq \widehat{p}_{1}^{\prime \prime}-\widehat{p}_{1}^{\prime \prime} \widehat{p_{2}} & \forall \widehat{p}_{1}^{\prime} \geq \widehat{p}_{1}^{\prime \prime}, \\
\widehat{p}_{1}^{\prime} \geq \widehat{p}_{1}^{\prime \prime}+\left(\widehat{p}_{1}^{\prime}-\widehat{p}_{1}^{\prime \prime}\right) \widehat{p_{2}} & \forall{\widehat{p_{1}}}^{\prime} \geq{\widehat{p_{1}}}^{\prime \prime}, \\
1 \geq \widehat{p_{2}} & \forall{\widehat{p_{1}}}^{\prime} \geq{\widehat{p_{1}}}^{\prime \prime} .
\end{array}
$$

Equation (A11) is true since $\widehat{p_{2}} \in(0,1)$. This means that no matter how many people we evacuated at time period 2 , the more people evacuated at time period 1 will lead to a bigger number of total evacuees.

We now consider another case of three time periods $(T=3)$ with other conditions being the same as the two time period case. The model is shown as follows:

$$
\operatorname{Max} \quad Z=\sum_{j \in J} n_{1} p_{j 1} x_{j 1}+\sum_{j \in J} n_{2} p_{j 2} x_{j 2}+\sum_{j \in J} n_{3} p_{j 3} x_{j 3},
$$

Subject to

$$
\begin{gathered}
\sum_{j \in J} x_{j t} \leq 1 \quad \forall t \in T, \\
x_{j t} \in\{0,1\} \quad \forall j \in J, \forall t \in T, \\
n_{t+1}=n_{t}-\sum_{j \in J} n_{t} p_{j t} x_{j t .} .
\end{gathered}
$$


Similar to the two time period case, we set $\widehat{p_{1}}=\sum_{j \in J} p_{j 1} \widehat{x_{j 1}}, \widehat{p_{2}}=\sum_{j \in J} p_{j 2} \widehat{x_{j 2}}$ and $\widehat{p_{3}}=\sum_{j \in J} p_{j 3} \widehat{x_{j 3}}$. Then, $\widehat{p_{1}} \in(0,1), \widehat{p_{2}} \in(0,1)$, and $\widehat{p_{3}} \in(0,1)$. We can obtain

$$
\begin{aligned}
\widehat{Z}=\widehat{Z_{1}}+\widehat{Z_{2}}+\widehat{Z_{3}} & =n_{1} \widehat{p_{1}}+n_{2} \widehat{p_{2}}+n_{3} \widehat{p_{3}} \\
& =n_{1} \widehat{p_{1}}+n_{1}\left(1-\widehat{p_{1}}\right) \widehat{p_{2}}+n_{1}\left(1-\widehat{p_{1}}\right)\left(1-\widehat{p_{2}}\right) \widehat{p_{3}} \\
& =n_{1}\left\{\left(\widehat{p_{1}}+\widehat{p_{2}}-\widehat{p_{1}} \widehat{p_{2}}\right)+\left[1-\left(\widehat{p_{1}}+\widehat{p_{2}}-\widehat{p_{1}} \widehat{p_{2}}\right)\right] \widehat{p_{3}}\right\} .
\end{aligned}
$$

Let $\widehat{p_{12}}$ be the average evacuation proportion in time period 1 to 2 , so $\widehat{p_{12}} \in(0,1)$, and we have

$$
\begin{aligned}
\widehat{p_{12}} & =\frac{\widehat{Z_{1}}+\widehat{Z_{2}}}{n_{1}} \\
& =\frac{n_{1} \widehat{p_{1}}+n_{2} \widehat{p_{2}}}{n_{1}} \\
& =\frac{n_{1}\left(\widehat{p_{1}}+\widehat{p_{2}}-\widehat{p_{1}} \widehat{n_{2}}\right)}{n_{1}} \\
& =\widehat{p_{1}}+\widehat{p_{2}}-\widehat{p_{1}} \widehat{p_{2}} .
\end{aligned}
$$

According to Equation (A18), we get the total evacuees number of the three time period as:

$$
\begin{aligned}
\widehat{Z} & =n_{1}\left[\widehat{p_{12}}+\left(1-\widehat{p_{12}}\right) \widehat{p_{3}}\right] \\
& =n_{1}\left(\widehat{p_{12}}+\widehat{p_{3}}-\widehat{p_{12}} \widehat{p_{3}}\right) .
\end{aligned}
$$

Since Equation (A24) is as the same formula as Equation (A7), the number of evacuees in the third time period $\left(\widehat{Z_{3}}\right)$ is equivalent to treating the first two time periods as one time period with updated evacuation rates, and $\widehat{p_{12}}$ and the third time period as the second time period in the previous example. This means that no matter how many people we evacuated at time period 3 , the more people evacuated at time periods 1 and 2 , the better it is.

Using induction, we can infer that in the single zone and single type of evacuee case with no congestion, in order to maximum the total number of evacuees, we need to evacuate as many people as we can at each time period. This is what the iterative scheme method does.

As the different population types do not share roadway capacity (Equations (6) and (7)), this can further be extended to multiple population groups, $i$.

\section{Appendix B. Counterexample for a Multiple Zone Case}

Consider the case of a single evacuee type, two zones, two time periods and two kinds of warning sources, which constitute four kinds of sending warning source types $(0,1,2,1 \& 2)$. The two zones share the same link with capacity $\left(C_{t}\right)$. Then, we have:

$$
\operatorname{Max} \quad Z^{\prime}=\sum_{j \in J} \sum_{k \in K} n_{k 1} p_{j 1} x_{j 1}+\sum_{j \in J} \sum_{k \in K} n_{k 2} p_{j 2} x_{j 2}
$$

Subject to

$$
\begin{array}{cc}
\sum_{j \in J} \sum_{k \in K} n_{k t} p_{j t} x_{j k t} \leq C_{t} & \forall t \in T, \\
\sum_{j \in J} x_{j k t} \leq 1 & \forall t \in T, \quad \forall k \in K, \\
x_{j k t} \in\{0,1\} & \forall j \in J, \quad \forall t \in T, \quad \forall k \in K, \\
n_{k 2}=n_{k 1}-\sum_{j \in J} n_{k 1} p_{j 1} x_{j k 1} & \forall k \in k .
\end{array}
$$


In this numerical experiment, all the input parameters are set as follows:

- Number of people need to be evacuate at beginning $(t=1)$ in different zone $\left(n_{k t}\right): n_{11}=100$, $n_{12}=200$;

- $\quad$ Capacity of different time $\left(C_{t}\right): C_{1}=75, C_{2}=80$;

- $\quad$ Response rate of different warning source type at different time $\left(p_{j t}\right): p_{11}=0, p_{21}=0.15$, $p_{31}=0.2, p_{41}=0.3, p_{12}=0, p_{22}=0.5, p_{32}=0.6, p_{42}=0.7$.

By using our iterative scheme, we firstly obtain the solution of time period $1,\left(x_{211}=1, x_{421}=1\right)$, and this strategy of time period 1 can evacuate 75 people $\left(Z_{1}^{\prime}=75\right)$. Then, we solve time period 2 and obtain the solution of time period $2\left(x_{112}=1, x_{222}=1\right)$, which can evacuate 70 people at time period $2\left(Z_{2}^{\prime}=70\right)$. This means that if we send the warning from source type 2 to zone 1 and from source type 4 to zone 2 in the first time period, then send the warning from source type 1 to zone 1 and from source type 2 to zone 2 in the second time period, there are 145 people that can be evacuated.

However, this solution is not the best solution in this situation. Sending another warning strategy can improve the solution. If we evacuate less people in zone 2 and more people in zone 1 during the first time period, more people could be evacuated $\left(x_{411}=1, x_{321}=1, x_{112}=1, x_{222}=1\right)$. The total number of evacuees in this case is $150\left(Z_{1}^{\prime}=70, Z_{2}^{\prime}=80\right)$.

\section{Appendix C. Parameter $p_{i j t}$ Used in the Case Study}

Table A1. The response rate $p_{i j t}$.

\begin{tabular}{|c|c|c|c|c|c|c|c|c|c|c|c|c|}
\hline & $t=1$ & $t=2$ & $t=3$ & $t=4$ & $t=5$ & $t=6$ & $t=7$ & $t=8$ & $t=9$ & $t=10$ & $t=11$ & $t=12$ \\
\hline$i_{1}, j=1$ & 0.132 & 0.332 & 0.232 & 0.132 & 0 & 0 & 0.032 & 0.632 & 0.732 & 0.632 & 0.532 & 0.332 \\
\hline$j=2$ & 0.134 & 0.334 & 0.234 & 0.134 & 0 & 0 & 0.034 & 0.634 & 0.734 & 0.634 & 0.534 & 0.334 \\
\hline$j=3$ & 0.136 & 0.336 & 0.236 & 0.136 & 0 & 0 & 0.036 & 0.636 & 0.736 & 0.636 & 0.536 & 0.336 \\
\hline$j=4$ & 0.138 & 0.338 & 0.238 & 0.138 & 0 & 0 & 0.038 & 0.638 & 0.738 & 0.638 & 0.538 & 0.338 \\
\hline$j=5$ & 0.152 & 0.352 & 0.252 & 0.152 & 0 & 0 & 0.052 & 0.652 & 0.752 & 0.652 & 0.552 & 0.353 \\
\hline$j=6$ & 0.153 & 0.353 & 0.253 & 0.153 & 0 & 0 & 0.053 & 0.653 & 0.753 & 0.653 & 0.553 & 0.353 \\
\hline$j=7$ & 0.154 & 0.354 & 0.254 & 0.154 & 0 & 0 & 0.054 & 0.654 & 0.754 & 0.654 & 0.554 & 0.354 \\
\hline$j=8$ & 0.155 & 0.355 & 0.255 & 0.155 & 0 & 0 & 0.055 & 0.655 & 0.755 & 0.655 & 0.555 & 0.355 \\
\hline$j=9$ & 0.156 & 0.356 & 0.256 & 0.156 & 0 & 0 & 0.056 & 0.656 & 0.756 & 0.656 & 0.556 & 0.356 \\
\hline$j=10$ & 0.157 & 0.357 & 0.257 & 0.157 & 0 & 0 & 0.057 & 0.657 & 0.757 & 0.657 & 0.557 & 0.357 \\
\hline$j=11$ & 0.172 & 0.372 & 0.272 & 0.172 & 0 & 0 & 0.072 & 0.672 & 0.772 & 0.672 & 0.572 & 0.372 \\
\hline$j=12$ & 0.174 & 0.374 & 0.274 & 0.174 & 0 & 0 & 0.074 & 0.674 & 0.774 & 0.674 & 0.574 & 0.374 \\
\hline$j=13$ & 0.176 & 0.376 & 0.276 & 0.176 & 0 & 0 & 0.076 & 0.676 & 0.776 & 0.676 & 0.576 & 0.376 \\
\hline$j=14$ & 0.178 & 0.378 & 0.278 & 0.178 & 0 & 0 & 0.078 & 0.678 & 0.778 & 0.678 & 0.578 & 0.378 \\
\hline$j=15$ & 0.19 & 0.39 & 0.29 & 0.19 & 0 & 0 & 0.09 & 0.69 & 0.79 & 0.69 & 0.59 & 0.39 \\
\hline$i_{2}, j=1$ & 0.122 & 0.322 & 0.222 & 0.122 & 0 & 0 & 0.022 & 0.622 & 0.722 & 0.622 & 0.522 & 0.322 \\
\hline$j=2$ & 0.124 & 0.324 & 0.224 & 0.124 & 0 & 0 & 0.024 & 0.624 & 0.724 & 0.624 & 0.524 & 0.324 \\
\hline$j=3$ & 0.126 & 0.326 & 0.226 & 0.126 & 0 & 0 & 0.026 & 0.626 & 0.726 & 0.626 & 0.526 & 0.326 \\
\hline$j=4$ & 0.128 & 0.328 & 0.228 & 0.128 & 0 & 0 & 0.028 & 0.628 & 0.728 & 0.628 & 0.528 & 0.328 \\
\hline$j=5$ & 0.142 & 0.342 & 0.242 & 0.142 & 0 & 0 & 0.042 & 0.642 & 0.742 & 0.642 & 0.542 & 0.342 \\
\hline$j=6$ & 0.143 & 0.343 & 0.243 & 0.143 & 0 & 0 & 0.043 & 0.643 & 0.743 & 0.643 & 0.543 & 0.343 \\
\hline$j=7$ & 0.144 & 0.344 & 0.244 & 0.144 & 0 & 0 & 0.044 & 0.644 & 0.744 & 0.644 & 0.544 & 0.344 \\
\hline$j=8$ & 0.145 & 0.345 & 0.245 & 0.145 & 0 & 0 & 0.045 & 0.645 & 0.745 & 0.645 & 0.545 & 0.345 \\
\hline$j=9$ & 0.146 & 0.346 & 0.246 & 0.146 & 0 & 0 & 0.046 & 0.646 & 0.746 & 0.646 & 0.546 & 0.346 \\
\hline$j=10$ & 0.147 & 0.347 & 0.247 & 0.147 & 0 & 0 & 0.047 & 0.647 & 0.747 & 0.647 & 0.547 & 0.347 \\
\hline$j=11$ & 0.162 & 0.362 & 0.262 & 0.162 & 0 & 0 & 0.062 & 0.662 & 0.762 & 0.662 & 0.562 & 0.362 \\
\hline$j=12$ & 0.164 & 0.364 & 0.264 & 0.164 & 0 & 0 & 0.064 & 0.664 & 0.764 & 0.664 & 0.564 & 0.364 \\
\hline$j=13$ & 0.166 & 0.366 & 0.266 & 0.166 & 0 & 0 & 0.066 & 0.666 & 0.766 & 0.666 & 0.566 & 0.366 \\
\hline$j=14$ & 0.168 & 0.368 & 0.268 & 0.168 & 0 & 0 & 0.068 & 0.668 & 0.768 & 0.668 & 0.568 & 0.368 \\
\hline$j=15$ & 0.18 & 0.38 & 0.28 & 0.18 & 0 & 0 & 0.08 & 0.68 & 0.78 & 0.68 & 0.58 & 0.38 \\
\hline
\end{tabular}




\section{Appendix D. Results of the Case Study}

Table A2. Brooklyn evacuation warning issuance schedule.

\begin{tabular}{|c|c|c|c|c|c|c|c|c|c|c|c|c|}
\hline Zone/Time & T1 & T2 & T3 & $\mathrm{T} 4$ & T5 & T6 & T7 & T8 & T9 & T10 & T11 & T12 \\
\hline $\mathrm{Z1}$ & 15 & 15 & 15 & 15 & 0 & 0 & 15 & 15 & 15 & 15 & 15 & 15 \\
\hline $\mathrm{Z2}$ & 15 & 15 & 15 & 15 & 0 & 0 & 15 & 15 & 15 & 15 & 15 & 15 \\
\hline $\mathrm{Z3}$ & 15 & 15 & 15 & 15 & 0 & 0 & 15 & 15 & 15 & 15 & 15 & 15 \\
\hline $\mathrm{Z} 4$ & 15 & 15 & 15 & 15 & 0 & 0 & 15 & 15 & 15 & 15 & 15 & 15 \\
\hline $\mathrm{Z} 5$ & 15 & 15 & 15 & 15 & 0 & 0 & 15 & 15 & 15 & 15 & 15 & 15 \\
\hline Z6 & 15 & 15 & 15 & 15 & 0 & 0 & 15 & 15 & 15 & 15 & 15 & 15 \\
\hline $\mathrm{Z7}$ & 15 & 15 & 15 & 15 & 0 & 0 & 15 & 15 & 15 & 15 & 15 & 15 \\
\hline Z8 & 15 & 15 & 15 & 15 & 0 & 0 & 15 & 15 & 15 & 15 & 15 & 15 \\
\hline Z9 & 15 & 15 & 15 & 15 & 0 & 0 & 15 & 15 & 15 & 15 & 15 & 15 \\
\hline Z10 & 15 & 15 & 15 & 15 & 0 & 0 & 15 & 15 & 15 & 15 & 15 & 15 \\
\hline Z11 & 15 & 15 & 15 & 15 & 0 & 0 & 15 & 15 & 15 & 15 & 15 & 15 \\
\hline Z12 & 15 & 15 & 15 & 15 & 0 & 0 & 15 & 15 & 15 & 15 & 15 & 15 \\
\hline Z13 & 0 & 0 & 15 & 15 & 0 & 0 & 15 & 15 & 15 & 15 & 15 & 15 \\
\hline Z14 & 15 & 0 & 15 & 15 & 0 & 0 & 15 & 15 & 15 & 15 & 15 & 15 \\
\hline Z15 & 15 & 10 & 15 & 15 & 0 & 0 & 15 & 15 & 15 & 15 & 15 & 15 \\
\hline Z16 & 15 & 15 & 15 & 15 & 0 & 0 & 15 & 15 & 15 & 15 & 15 & 15 \\
\hline Z17 & 15 & 15 & 15 & 15 & 0 & 0 & 15 & 15 & 15 & 15 & 15 & 15 \\
\hline Z18 & 15 & 15 & 15 & 15 & 0 & 0 & 15 & 15 & 15 & 15 & 15 & 15 \\
\hline Z19 & 15 & 15 & 15 & 15 & 0 & 0 & 15 & 15 & 15 & 15 & 15 & 15 \\
\hline Z20 & 15 & 15 & 15 & 15 & 0 & 0 & 15 & 15 & 15 & 15 & 15 & 15 \\
\hline Z21 & 15 & 15 & 15 & 15 & 0 & 0 & 15 & 15 & 15 & 15 & 15 & 15 \\
\hline Z22 & 15 & 15 & 15 & 15 & 0 & 0 & 15 & 15 & 15 & 15 & 15 & 15 \\
\hline Z23 & 15 & 15 & 15 & 15 & 0 & 0 & 15 & 15 & 15 & 15 & 15 & 15 \\
\hline Z24 & 15 & 15 & 15 & 15 & 0 & 0 & 15 & 15 & 15 & 15 & 15 & 15 \\
\hline Z25 & 15 & 15 & 15 & 15 & 0 & 0 & 15 & 15 & 15 & 15 & 15 & 15 \\
\hline Z26 & 15 & 15 & 15 & 15 & 0 & 0 & 15 & 15 & 15 & 15 & 15 & 15 \\
\hline Z27 & 15 & 15 & 15 & 15 & 0 & 0 & 15 & 15 & 15 & 15 & 15 & 15 \\
\hline Z28 & 15 & 15 & 15 & 15 & 0 & 0 & 15 & 15 & 15 & 15 & 15 & 15 \\
\hline Z29 & 15 & 15 & 15 & 15 & 0 & 0 & 15 & 15 & 15 & 15 & 15 & 15 \\
\hline Z30 & 15 & 15 & 15 & 15 & 0 & 0 & 15 & 15 & 15 & 15 & 15 & 15 \\
\hline Z31 & 15 & 15 & 15 & 15 & 0 & 0 & 15 & 15 & 15 & 15 & 15 & 15 \\
\hline Z32 & 15 & 15 & 15 & 15 & 0 & 0 & 15 & 15 & 15 & 15 & 15 & 15 \\
\hline Z33 & 15 & 15 & 15 & 15 & 0 & 0 & 15 & 15 & 15 & 15 & 15 & 15 \\
\hline Z34 & 15 & 15 & 15 & 15 & 0 & 0 & 15 & 15 & 15 & 15 & 15 & 15 \\
\hline Z35 & 15 & 15 & 15 & 15 & 0 & 0 & 15 & 15 & 15 & 15 & 15 & 15 \\
\hline Z36 & 15 & 15 & 15 & 15 & 0 & 0 & 15 & 15 & 15 & 15 & 15 & 15 \\
\hline Z37 & 15 & 15 & 15 & 15 & 0 & 0 & 15 & 15 & 15 & 15 & 15 & 15 \\
\hline Z38 & 15 & 0 & 15 & 15 & 0 & 0 & 15 & 15 & 15 & 15 & 15 & 15 \\
\hline Z39 & 15 & 15 & 15 & 15 & 0 & 0 & 15 & 15 & 15 & 15 & 15 & 15 \\
\hline $\mathrm{Z} 40$ & 15 & 15 & 15 & 15 & 0 & 0 & 15 & 15 & 15 & 15 & 15 & 15 \\
\hline Z41 & 15 & 15 & 15 & 15 & 0 & 0 & 15 & 15 & 15 & 15 & 15 & 15 \\
\hline $\mathrm{Z} 42$ & 0 & 0 & 0 & 15 & 0 & 0 & 15 & 0 & 9 & 15 & 15 & 15 \\
\hline $\mathrm{Z} 43$ & 15 & 15 & 15 & 15 & 0 & 0 & 15 & 15 & 15 & 15 & 15 & 15 \\
\hline Z44 & 15 & 15 & 15 & 15 & 0 & 0 & 15 & 15 & 15 & 15 & 15 & 15 \\
\hline Z45 & 15 & 15 & 15 & 15 & 0 & 0 & 15 & 15 & 15 & 15 & 15 & 15 \\
\hline Z46 & 15 & 15 & 15 & 15 & 0 & 0 & 15 & 15 & 15 & 15 & 15 & 15 \\
\hline Z47 & 15 & 15 & 15 & 15 & 0 & 0 & 15 & 15 & 15 & 15 & 15 & 15 \\
\hline Z48 & 15 & 15 & 15 & 15 & 0 & 0 & 15 & 15 & 15 & 15 & 15 & 15 \\
\hline Z49 & 15 & 15 & 15 & 15 & 0 & 0 & 15 & 15 & 15 & 15 & 15 & 15 \\
\hline $\mathrm{Z} 50$ & 15 & 15 & 15 & 15 & 0 & 0 & 15 & 15 & 15 & 15 & 15 & 15 \\
\hline Z51 & 15 & 15 & 15 & 15 & 0 & 0 & 15 & 15 & 15 & 15 & 15 & 15 \\
\hline Z52 & 15 & 15 & 15 & 15 & 0 & 0 & 15 & 15 & 15 & 15 & 15 & 15 \\
\hline Z53 & 15 & 0 & 15 & 15 & 0 & 0 & 15 & 15 & 15 & 15 & 15 & 15 \\
\hline Z54 & 1 & 0 & 15 & 15 & 0 & 0 & 15 & 0 & 5 & 15 & 15 & 15 \\
\hline
\end{tabular}


Table A2. Cont.

\begin{tabular}{ccccccccccccc}
\hline Zone/Time & T1 & T2 & T3 & T4 & T5 & T6 & T7 & T8 & T9 & T10 & T11 & T12 \\
\hline Z55 & 15 & 15 & 15 & 15 & 0 & 0 & 15 & 15 & 15 & 15 & 15 & 15 \\
Z56 & 15 & 15 & 15 & 15 & 0 & 0 & 15 & 15 & 15 & 15 & 15 & 15 \\
Z57 & 0 & 0 & 0 & 15 & 0 & 0 & 15 & 0 & 0 & 15 & 15 & 15 \\
Z58 & 0 & 0 & 0 & 15 & 0 & 0 & 15 & 10 & 12 & 15 & 15 & 15 \\
Z59 & 0 & 0 & 0 & 15 & 0 & 0 & 15 & 0 & 0 & 15 & 15 & 15 \\
Z60 & 0 & 0 & 0 & 15 & 0 & 0 & 15 & 0 & 12 & 15 & 15 & 15 \\
Z61 & 0 & 0 & 0 & 15 & 0 & 0 & 15 & 0 & 10 & 15 & 15 & 15 \\
Z62 & 0 & 0 & 0 & 15 & 0 & 0 & 15 & 13 & 15 & 15 & 15 & 15 \\
Z63 & 0 & 0 & 1 & 15 & 0 & 0 & 15 & 0 & 12 & 15 & 15 & 15 \\
Z64 & 1 & 4 & 0 & 15 & 0 & 0 & 15 & 13 & 0 & 15 & 15 & 15 \\
Z65 & 5 & 0 & 0 & 15 & 0 & 0 & 15 & 0 & 0 & 15 & 15 & 15 \\
Z66 & 15 & 15 & 15 & 15 & 0 & 0 & 15 & 15 & 15 & 15 & 15 & 15 \\
Z67 & 15 & 15 & 15 & 15 & 0 & 0 & 15 & 15 & 15 & 15 & 15 & 15 \\
Z68 & 15 & 15 & 15 & 15 & 0 & 0 & 15 & 15 & 15 & 15 & 15 & 15 \\
Z69 & 15 & 15 & 15 & 15 & 0 & 0 & 15 & 15 & 15 & 15 & 15 & 15 \\
Z70 & 0 & 0 & 1 & 15 & 0 & 0 & 15 & 6 & 7 & 15 & 15 & 15 \\
Z71 & 15 & 15 & 15 & 15 & 0 & 0 & 15 & 15 & 15 & 15 & 15 & 15 \\
\hline
\end{tabular}

Appendix E. The Updated $p_{i j t}$

Table A3. The adjusted response rate $p_{i j t}$.

\begin{tabular}{|c|c|c|c|c|c|c|}
\hline & $t=2$ & $t=8$ & $t=9$ & $t=10$ & $t=11$ & $t=12$ \\
\hline$i_{1}, j=1$ & 0.432 & 0.732 & 0.632 & 0.432 & 0.332 & 0.132 \\
\hline$j=2$ & 0.434 & 0.734 & 0.634 & 0.434 & 0.334 & 0.134 \\
\hline$j=3$ & 0.436 & 0.736 & 0.636 & 0.436 & 0.336 & 0.136 \\
\hline$j=4$ & 0.438 & 0.738 & 0.638 & 0.438 & 0.338 & 0.138 \\
\hline$j=5$ & 0.452 & 0.752 & 0.652 & 0.452 & 0.352 & 0.152 \\
\hline$j=6$ & 0.453 & 0.753 & 0.653 & 0.453 & 0.353 & 0.153 \\
\hline$j=7$ & 0.454 & 0.754 & 0.654 & 0.454 & 0.354 & 0.154 \\
\hline$j=8$ & 0.455 & 0.755 & 0.655 & 0.455 & 0.355 & 0.155 \\
\hline$j=9$ & 0.456 & 0.756 & 0.656 & 0.456 & 0.356 & 0.156 \\
\hline$j=10$ & 0.457 & 0.757 & 0.657 & 0.457 & 0.357 & 0.157 \\
\hline$j=11$ & 0.472 & 0.772 & 0.672 & 0.472 & 0.372 & 0.172 \\
\hline$j=12$ & 0.474 & 0.774 & 0.674 & 0.474 & 0.374 & 0.174 \\
\hline$j=13$ & 0.476 & 0.776 & 0.676 & 0.476 & 0.376 & 0.176 \\
\hline$j=14$ & 0.478 & 0.778 & 0.678 & 0.478 & 0.378 & 0.178 \\
\hline$j=15$ & 0.49 & 0.79 & 0.69 & 0.49 & 0.39 & 0.19 \\
\hline$i_{2}, j=1$ & 0.422 & 0.722 & 0.622 & 0.422 & 0.322 & 0.122 \\
\hline$j=2$ & 0.424 & 0.724 & 0.624 & 0.424 & 0.324 & 0.124 \\
\hline$j=3$ & 0.426 & 0.726 & 0.626 & 0.426 & 0.326 & 0.126 \\
\hline$j=4$ & 0.428 & 0.728 & 0.628 & 0.428 & 0.328 & 0.128 \\
\hline$j=5$ & 0.442 & 0.742 & 0.642 & 0.442 & 0.342 & 0.142 \\
\hline$j=6$ & 0.443 & 0.743 & 0.643 & 0.443 & 0.343 & 0.143 \\
\hline$j=7$ & 0.444 & 0.744 & 0.644 & 0.444 & 0.344 & 0.144 \\
\hline$j=8$ & 0.445 & 0.745 & 0.645 & 0.445 & 0.345 & 0.145 \\
\hline$j=9$ & 0.446 & 0.746 & 0.646 & 0.446 & 0.346 & 0.146 \\
\hline$j=10$ & 0.447 & 0.747 & 0.647 & 0.447 & 0.347 & 0.147 \\
\hline$j=11$ & 0.462 & 0.762 & 0.662 & 0.462 & 0.362 & 0.162 \\
\hline$j=12$ & 0.464 & 0.764 & 0.664 & 0.464 & 0.364 & 0.164 \\
\hline$j=13$ & 0.466 & 0.766 & 0.666 & 0.466 & 0.366 & 0.166 \\
\hline$j=14$ & 0.468 & 0.768 & 0.668 & 0.568 & 0.368 & 0.168 \\
\hline$j=15$ & 0.48 & 0.78 & 0.68 & 0.48 & 0.38 & 0.18 \\
\hline
\end{tabular}




\section{Appendix F. Result of $p_{i j t}$ Adjustment}

Table A4. Brooklyn evacuation warning issuance schedule with updated $p_{i j t}$.

\begin{tabular}{|c|c|c|c|c|c|c|c|c|c|c|c|c|}
\hline Zone/Time & T1 & $\mathrm{T} 2$ & T3 & $\mathrm{T} 4$ & T5 & T6 & $\mathrm{T} 7$ & $\mathrm{~T} 8$ & T9 & T10 & T11 & T12 \\
\hline $\mathrm{Z1}$ & 15 & 15 & 15 & 15 & 0 & 0 & 15 & 15 & 15 & 15 & 15 & 15 \\
\hline $\mathrm{Z2}$ & 15 & 15 & 15 & 15 & 0 & 0 & 15 & 15 & 15 & 15 & 15 & 15 \\
\hline $\mathrm{Z3}$ & 15 & 15 & 15 & 15 & 0 & 0 & 15 & 15 & 15 & 15 & 15 & 15 \\
\hline $\mathrm{Z} 4$ & 15 & 11 & 15 & 15 & 0 & 0 & 15 & 15 & 15 & 15 & 15 & 15 \\
\hline $\mathrm{Z} 5$ & 15 & 15 & 15 & 15 & 0 & 0 & 15 & 15 & 15 & 15 & 15 & 15 \\
\hline Z6 & 15 & 15 & 15 & 15 & 0 & 0 & 15 & 15 & 15 & 15 & 15 & 15 \\
\hline $\mathrm{Z7}$ & 15 & 15 & 15 & 15 & 0 & 0 & 15 & 15 & 15 & 15 & 15 & 15 \\
\hline Z8 & 15 & 15 & 15 & 15 & 0 & 0 & 15 & 15 & 15 & 15 & 15 & 15 \\
\hline Z9 & 15 & 15 & 15 & 15 & 0 & 0 & 15 & 15 & 15 & 15 & 15 & 15 \\
\hline Z10 & 15 & 15 & 15 & 15 & 0 & 0 & 15 & 15 & 15 & 15 & 15 & 15 \\
\hline Z11 & 15 & 15 & 15 & 15 & 0 & 0 & 15 & 15 & 15 & 15 & 15 & 15 \\
\hline $\mathrm{Z} 12$ & 15 & 15 & 15 & 15 & 0 & 0 & 15 & 15 & 15 & 15 & 15 & 15 \\
\hline Z13 & 0 & 0 & 15 & 15 & 0 & 0 & 15 & 15 & 15 & 15 & 15 & 15 \\
\hline Z14 & 15 & 0 & 15 & 15 & 0 & 0 & 15 & 15 & 15 & 15 & 15 & 15 \\
\hline Z15 & 15 & 0 & 15 & 15 & 0 & 0 & 15 & 15 & 15 & 15 & 15 & 15 \\
\hline Z16 & 15 & 15 & 15 & 15 & 0 & 0 & 15 & 15 & 15 & 15 & 15 & 15 \\
\hline $\mathrm{Z} 17$ & 15 & 15 & 15 & 15 & 0 & 0 & 15 & 15 & 15 & 15 & 15 & 15 \\
\hline Z18 & 15 & 15 & 15 & 15 & 0 & 0 & 15 & 15 & 15 & 15 & 15 & 15 \\
\hline Z19 & 15 & 4 & 15 & 15 & 0 & 0 & 15 & 15 & 15 & 15 & 15 & 15 \\
\hline Z20 & 15 & 15 & 15 & 15 & 0 & 0 & 15 & 15 & 15 & 15 & 15 & 15 \\
\hline $\mathrm{Z} 21$ & 15 & 15 & 15 & 15 & 0 & 0 & 15 & 15 & 15 & 15 & 15 & 15 \\
\hline $\mathrm{Z} 22$ & 15 & 15 & 15 & 15 & 0 & 0 & 15 & 15 & 15 & 15 & 15 & 15 \\
\hline Z23 & 15 & 15 & 15 & 15 & 0 & 0 & 15 & 15 & 15 & 15 & 15 & 15 \\
\hline Z24 & 15 & 15 & 15 & 15 & 0 & 0 & 15 & 15 & 15 & 15 & 15 & 15 \\
\hline Z25 & 15 & 15 & 15 & 15 & 0 & 0 & 15 & 15 & 15 & 15 & 15 & 15 \\
\hline $\mathrm{Z} 26$ & 15 & 15 & 15 & 15 & 0 & 0 & 15 & 15 & 15 & 15 & 15 & 15 \\
\hline Z27 & 15 & 15 & 15 & 15 & 0 & 0 & 15 & 15 & 15 & 15 & 15 & 15 \\
\hline Z28 & 15 & 15 & 15 & 15 & 0 & 0 & 15 & 15 & 15 & 15 & 15 & 15 \\
\hline Z29 & 15 & 15 & 15 & 15 & 0 & 0 & 15 & 15 & 15 & 15 & 15 & 15 \\
\hline $\mathrm{Z} 30$ & 15 & 15 & 15 & 15 & 0 & 0 & 15 & 15 & 15 & 15 & 15 & 15 \\
\hline Z31 & 15 & 15 & 15 & 15 & 0 & 0 & 15 & 15 & 15 & 15 & 15 & 15 \\
\hline $\mathrm{Z} 32$ & 15 & 15 & 15 & 15 & 0 & 0 & 15 & 15 & 15 & 15 & 15 & 15 \\
\hline Z33 & 15 & 15 & 15 & 15 & 0 & 0 & 15 & 15 & 15 & 15 & 15 & 15 \\
\hline Z34 & 15 & 15 & 15 & 15 & 0 & 0 & 15 & 15 & 15 & 15 & 15 & 15 \\
\hline Z35 & 15 & 15 & 15 & 15 & 0 & 0 & 15 & 15 & 15 & 15 & 15 & 15 \\
\hline Z36 & 15 & 15 & 15 & 15 & 0 & 0 & 15 & 15 & 15 & 15 & 15 & 15 \\
\hline Z37 & 15 & 15 & 15 & 15 & 0 & 0 & 15 & 15 & 15 & 15 & 15 & 15 \\
\hline Z38 & 15 & 0 & 15 & 15 & 0 & 0 & 15 & 15 & 15 & 15 & 15 & 15 \\
\hline Z39 & 15 & 15 & 15 & 15 & 0 & 0 & 15 & 15 & 15 & 15 & 15 & 15 \\
\hline $\mathrm{Z} 40$ & 15 & 15 & 15 & 15 & 0 & 0 & 15 & 15 & 15 & 15 & 15 & 15 \\
\hline Z41 & 15 & 15 & 15 & 15 & 0 & 0 & 15 & 15 & 15 & 15 & 15 & 15 \\
\hline Z42 & 0 & 0 & 0 & 15 & 0 & 0 & 15 & 0 & 15 & 15 & 15 & 15 \\
\hline Z43 & 15 & 15 & 15 & 15 & 0 & 0 & 15 & 15 & 15 & 15 & 15 & 15 \\
\hline $\mathrm{Z} 44$ & 15 & 15 & 15 & 15 & 0 & 0 & 15 & 15 & 15 & 15 & 15 & 15 \\
\hline $\mathrm{Z} 45$ & 15 & 15 & 15 & 15 & 0 & 0 & 15 & 15 & 15 & 15 & 15 & 15 \\
\hline Z46 & 15 & 15 & 15 & 15 & 0 & 0 & 15 & 15 & 15 & 15 & 15 & 15 \\
\hline $\mathrm{Z} 47$ & 15 & 15 & 15 & 15 & 0 & 0 & 15 & 15 & 15 & 15 & 15 & 15 \\
\hline Z48 & 15 & 15 & 15 & 15 & 0 & 0 & 15 & 15 & 15 & 15 & 15 & 15 \\
\hline Z49 & 15 & 15 & 15 & 15 & 0 & 0 & 15 & 15 & 15 & 15 & 15 & 15 \\
\hline $\mathrm{Z} 50$ & 15 & 15 & 15 & 15 & 0 & 0 & 15 & 15 & 15 & 15 & 15 & 15 \\
\hline Z51 & 15 & 15 & 15 & 15 & 0 & 0 & 15 & 15 & 15 & 15 & 15 & 15 \\
\hline Z52 & 15 & 15 & 15 & 15 & 0 & 0 & 15 & 15 & 15 & 15 & 15 & 15 \\
\hline Z53 & 15 & 0 & 15 & 15 & 0 & 0 & 15 & 15 & 15 & 15 & 15 & 15 \\
\hline Z54 & 1 & 0 & 0 & 15 & 0 & 0 & 15 & 1 & 5 & 15 & 15 & 15 \\
\hline Z55 & 15 & 15 & 15 & 15 & 0 & 0 & 15 & 15 & 15 & 15 & 15 & 15 \\
\hline
\end{tabular}


Table A4. Cont.

\begin{tabular}{ccccccccccccc}
\hline Zone/Time & T1 & T2 & T3 & T4 & T5 & T6 & T7 & T8 & T9 & T10 & T11 & T12 \\
\hline Z56 & 15 & 15 & 15 & 15 & 0 & 0 & 15 & 15 & 15 & 15 & 15 & 15 \\
Z57 & 0 & 0 & 0 & 15 & 0 & 0 & 15 & 0 & 14 & 15 & 15 & 15 \\
Z58 & 0 & 0 & 0 & 15 & 0 & 0 & 15 & 10 & 2 & 15 & 15 & 15 \\
Z59 & 0 & 0 & 0 & 15 & 0 & 0 & 15 & 10 & 3 & 15 & 15 & 15 \\
Z60 & 0 & 0 & 0 & 15 & 0 & 0 & 15 & 0 & 0 & 15 & 15 & 15 \\
Z61 & 0 & 0 & 0 & 15 & 0 & 0 & 15 & 0 & 0 & 15 & 15 & 15 \\
Z62 & 0 & 0 & 15 & 15 & 0 & 0 & 15 & 2 & 15 & 15 & 15 & 15 \\
Z63 & 0 & 0 & 1 & 15 & 0 & 0 & 15 & 0 & 15 & 15 & 15 & 15 \\
Z64 & 1 & 0 & 0 & 15 & 0 & 0 & 15 & 1 & 15 & 15 & 15 & 15 \\
Z65 & 5 & 15 & 11 & 15 & 0 & 0 & 15 & 0 & 15 & 15 & 15 & 15 \\
Z66 & 15 & 15 & 15 & 15 & 0 & 0 & 15 & 15 & 15 & 15 & 15 & 15 \\
Z67 & 15 & 15 & 15 & 15 & 0 & 0 & 15 & 15 & 15 & 15 & 15 & 15 \\
Z68 & 15 & 15 & 15 & 15 & 0 & 0 & 15 & 15 & 15 & 15 & 15 & 15 \\
Z69 & 15 & 15 & 15 & 15 & 0 & 0 & 15 & 15 & 15 & 15 & 15 & 15 \\
Z70 & 0 & 0 & 15 & 15 & 0 & 0 & 15 & 0 & 15 & 15 & 15 & 15 \\
Z71 & 15 & 15 & 15 & 15 & 0 & 0 & 15 & 15 & 15 & 15 & 15 & 15 \\
\hline
\end{tabular}

\section{References}

1. Benfield. October 2012 Global Catastrophe Recap Impact Forecasting, 2013. Available online: http:// thoughtleadership.aonbenfield.com/Documents/201211_if_monthly_cat_recap_october.pdf (accessed on 7 July 2016).

2. Sbayti, H.; Mahmassani, H. Optimal scheduling of evacuation operations. Transp. Res. Rec. 2006, 1964, 238-246.

3. Kulshrestha, A. Transit-Based Evacuation Planning under Demand Uncertainty; University of Florida: Gainesville, FL, USA, 2011.

4. Litman, T. Lessons from Katrina and Rita: What major disasters can teach transportation planners. J. Transp. Eng. 2006, 132, 11-18.

5. Brown, C.; White, W.; van Slyke, C.; Benson, J.D. Development of a strategic hurricane evacuation-dynamic traffic assignment model for the Houston, Texas, Region. Transp. Res. Rec. 2010, 2137, 46-53.

6. Sherali, H.D.; Carter, T.B.; Hobeika, A.G. A location-allocation model and algorithm for evacuation planning under hurricane/flood conditions. Transp. Res. Part B 1991, 25, 439-452.

7. Nisha de Silva, F. Providing spatial decision support for evacuation planning: A challenge in integrating technologies. Disaster Prev. Manag. Int. J. 2001, 10, 11-20.

8. Stein, R.; Buzcu-Guven, B.; Duenas-Osorio, L.; Subramanian, D.; Kahle, D. How risk perceptions influence evacuations from hurricanes and compliance with government directives. Policy Stud. J. 2013, 41, 319-342.

9. Pel, A. Model-based optimal evacuation planning anticipating traveler compliance behavior. In Proceedings of the 12th International Conference on Travel Behavior Research (IATBR), Jaipur, India, 13-18 December 2009; pp. 1-22.

10. Huang, S.K.; Wu, H.C.; Lindell, M.K.; Wei, H.L.; Samuelson, C.D. Perceptions, behavioral expectations, and implementation timing for response actions in a hurricane emergency. Nat. Hazards 2017, 88, 533-558.

11. Whitehead, J.C.; Edwards, B.; Van Willigen, M.; Maiolo, J.R.; Wilson, K.; Smith, K.T. Heading for higher ground: Factors affecting real and hypothetical hurricane evacuation behavior. Environ. Hazards 2000, 2, 133-142.

12. Riad, J.K.; Norris, F.H.; Ruback, R.B. Predicting Evacuation in Two Major Disasters: Risk Perception, Social Influence, and Access to Resources. J. Appl. Soc. Psychol. 1999, 25, 918-934.

13. Murray-Tuite, P.; Wolshon, B. Evacuation transportation modeling: An overview of research, development, and practice. Transp. Res. Part C 2013, 27, 25-45.

14. Wu, H.C.; Lindell, M.K.; Prater, C.S. Logistics of hurricane evacuation in Hurricanes Katrina and Rita. Transp. Res. Part F 2012, 15, 445-461. 
15. Deka, D.; Carnegie, J. Analyzing evacuation behavior of transportation-disadvantaged populations in northern New Jersey. In Proceedings of the Transportation Research Board 89th Annual Meeting, Washington, DC, USA, 1-10 January 2010.

16. Lindell, M.K.; Prater, C.S. Critical Behavioral Assumptions in Evacuation Time Estimate Analysis for Private Vehicles: Examples from Hurricane Research and Planning. J. Urban Plan. Dev. 2007, 133, 18-29.

17. Abdelgawad, H.; Abdulhai, B. Emergency evacuation planning as a network design problem: A critical review. Transp. Lett. 2009, 1, 41-58.

18. Lim, G.J.; Zangeneh, S.; Reza Baharnemati, M.; Assavapokee, T. A capacitated network flow optimization approach for short notice evacuation planning. Eur. J. Oper. Res. 2012, 223, 234-245.

19. Zheng, H.; Chiu, Y.C.; Mirchandani, P.; Hickman, M. Modeling of evacuation and background traffic for optimal zone-based vehicle evacuation strategy. Transp. Res. Rec. 2010, 2196, 65-74.

20. Renne, J.L.; Sanchez, T.W.; Litman, T. National study on carless and special needs evacuation planning: A literature review. In Planning and Urban Studies Reports and Presentations; University of New Orleans: New Orleans, LA, USA, 2008.

21. Renne, J.; Sanchez, T.; Jenkins, P.; Peterson, R. Challenge of evacuating the carless in five major US cities: Identifying the key issues. Transp. Res. Rec. 2009, 2119, 36-44.

22. Bish, D.R. Planning for a bus-based evacuation. OR Spectr. 2011, 33, 629-654.

23. Swamy, R.; Kang, J.E.; Batta, R.; Chung, Y. Hurricane evacuation planning using public transportation. Socioecon. Plan. Sci. 2017, 59, 43-55.

24. Pengel, B.; Shirshov, G.; Krzhizhanovskaya, V.; Melnikova, N.; Koelewijn, A.; Pyayt, A.; Mokhov, I. Flood Early Warning System: Sensors and Internet. Available online: http:/ / www.preventionweb.net/ publications / view / 32435 (accessed on 18 November 2017).

25. Lindell, M.K.; Perry, R.W. The protective action decision model: Theoretical modifications and additional evidence. Risk Anal. 2012, 32, 616-632.

26. Lindell, M.K.; Perry, R.W. Communicating Environmental Risk in Multiethnic Communities; Sage Publications: Thousand Oaks, CA, USA, 2004; p. 262.

27. Lindell, M.K.; Lu, J.C.; Prater, C.S. Household decision making and evacuation in response to Hurricane Lili. Nat. Hazards Rev. 2005, 6, 171-179.

28. Cahyanto, I.; Pennington-Gray, L.; Thapa, B.; Srinivasan, S.; Villegas, J.; Matyas, C.; Kiousis, S. Predicting information seeking regarding hurricane evacuation in the destination. Tour. Manag. 2016, 52, 264-275.

29. Dow, K.; Cutter, S.L. Crying wolf: Repeat responses to hurricane evacuation orders. Coast. Manag. 1998, 26, 237-252.

30. Prater, C.; Wenger, D.; Grady, K. Hurricane Bret Post Storm Assessment: A Review of the Utilization of Hurricane Evacuation Studies and Information Dissemination; Hazard Reduction \& Recovery Center, Texas A\&M University: College Station, TX, USA, 2000.

31. Taaffe, K.; Garrett, S.; Huang, Y.H.; Nkwocha, I. Communication's role and technology preferences during hurricane evacuations. Nat. Hazards Rev. 2013, 14, 182-190.

32. Burnside, R.; Miller, D.S.; Rivera, J.D. the Impact of Information and Risk Perception on the Hurricane Evacuation Decision-Making of Greater New Orleans Residents. Sociol. Spectr. 2007, 27, 727-740.

33. Lindell, M.K.; Prater, C.S.; Peacock, W.G. Organizational communication and decision making for hurricane emergencies. Nat. Hazards Rev. 2007, 8, 50-60.

34. Dow, K.; Cutter, S.L. Public orders and personal opinions: Household strategies for hurricane risk assessment. Glob. Environ. Chang. Part B 2000, 2, 143-155.

35. West, D.M.; Orr, M. Race, gender, and communications in natural disasters. Policy Stud. J. 2007, 35, 569-586.

36. FEMA. How to Prepare for a Hurricane; Technical Report; Federal Emergency Management Agency: Washington, DC, USA, 2014.

37. Durage, S.W.; Kattan, L.; Wirasinghe, S.C.; Ruwanpura, J.Y. Evacuation behaviour of households and drivers during a tornado. Nat. Hazards 2014, 71, 1495-1517.

38. Driscoll, P.; Salwen, M.B. Riding out the storm: Public evaluations of news coverage of Hurricane Andrew. Int. J. Mass Emerg. Disasters 1996, 14, 293-303.

39. Bokuniewicz, H.; Tanski, J. Assessment of the Base Evacuation Plan in Nassau County; Technical Report NYSRISE-TR-14; New York State Institute for Storms and Emergencies: New York, NY, USA, 2014. 
40. Sutton, J.; Palen, L.; Shklovski, I. Backchannels on the front lines: Emergent uses of social media in the 2007 southern California wildfires. In Proceedings of the 5th International ISCRAM Conference, Washington, DC, USA, 4-7 May 2008; pp. 624-632.

41. Arlikatti, S. Risk area accuracy and hurricane evacuation expectations of coastal residents. Environ. Behav. 2006, 38, 226-247.

42. Gibbs, L.; Holloway, C. Hurricane Sandy after Action: Report and Recommendations to Mayor Michael R. Bloomberg; Technical Report; The City of New York: New York, NY, USA, 2013.

43. Post, Buckley, Schuh, and Jernigan, Inc. Mississippi Transportation Analysis Final Report; Technical Report; Federal Emergency Management Agency: Washington, DC, USA, 2001.

44. Fothergill, A.; Maestas, E.G.; Darlington, J.D. Race, ethnicity and disasters in the United States: A review of the literature. Disasters 1999, 23, 156-173.

45. Bateman, J.M.; Edwards, B. Gender and evacuation: A closer look at why women are more likely to evacuate for hurricanes. Nat. Hazards Rev. 2002, 3, 107-117.

46. Fothergill, A.; Peek, L.A. Poverty and disasters in the United States: A review of recent sociological findings. Nat. Hazards 2004, 32, 89-110.

47. Brodie, M.; Weltzien, E.; Altman, D.; Blendon, R.J.; Benson, J.M. Experiences of Hurricane Katrina evacuees in Houston shelters: Implications for future planning. Am. J. Public Health 2006, 96, 1402-1408.

48. Phillips, B.D.; Morrow, B.H. Social science research needs: Focus on vulnerable populations, forecasting, and warnings. Nat. Hazards Rev. 2007, 8, 61-68.

49. Gudishala, R.; Wilmot, C. Comparison of Time-Dependent Sequential Logit and Nested Logit for Modeling Hurricane Evacuation Demand. Transp. Res. Rec. 2012, 2312, 134-140.

50. Cahyanto, I.; Pennington-Gray, L.; Thapa, B.; Srinivasan, S.; Villegas, J.; Matyas, C.; Kiousis, S. An empirical evaluation of the determinants of tourist's hurricane evacuation decision making. J. Destin. Mark. Manag. 2014, 2, 253-265.

51. Huang, S.K.; Lindell, M.K.; Prater, C.S.; Wu, H.C.; Siebeneck, L.K. Household evacuation decision making in response to Hurricane Ike. Nat. Hazards Rev. 2012, 13, 283-296.

52. Sadri, A.M.; Ukkusuri, S.V.; Murray-Tuite, P.; Gladwin, H. Analysis of hurricane evacuee mode choice behavior. Transp. Res. Part C 2014, 48, 37-46.

53. Fu, H.; Wilmot, C. A Sequential logit dynamic travel demand model for hurricane evacuation. Transp. Res. Rec. 2004, 1882, 19-26.

54. Eisenman, D.P.; Cordasco, K.M.; Asch, S.; Golden, J.F.; Glik, D. Disaster Planning and Risk Communication With Vulnerable Communities: Lessons From Hurricane Katrina. Am. J. Public Health 2007, 97, S109-S115.

55. Raggatt, P.; Butterworth, E.; Morrissey, S. Issues in natural disaster management: community response to the threat of tropical cyclones in Australia. Disaster Prev. Manag. Int. J. 1993, 2, doi:10.1108/09653569310040955.

56. Pel, A.J.; Bliemer, M.C.J.; Hoogendoorn, S.P. EVAQ: A new analytical model for voluntary and mandatory evacuation strategies on time-varying networks. In Proceedings of the IEEE Conference on Intelligent Transportation Systems, ITSC, Beijing, China, 12-15 October 2008; pp. 528-533.

57. Gladwin, C.H.; Gladwin, H.; Peacock, W.G. Modeling hurricane evacuation decisions with ethnographic methods. Int. J. Mass Emerg. Disasters 2001, 19, 117-143.

58. Wilmot, C.G.; Mei, B. Comparison of alternative trip generation models for hurricane evacuation. Nat. Hazards Rev. 2004, 5, 170-178.

59. Zhang, Y.; Prater, C.S.; Lindell, M.K. Risk Area Accuracy and Evacuation from Hurricane Bret. Nat. Hazards Rev. 2004, 5, 115-120.

60. Whitehead, J.C. Environmental risk and averting behavior: Predictive validity of jointly estimated revealed and stated behavior data. Environ. Resour. Econ. 2005, 32, 301-316.

61. Lindell, M.; Prater, C. Behavioral Analysis: Texas Hurricane Evacuation Study; Hazard Reduction \& Recovery Center, Texas A\&M University: College Station, TX, USA, 2008.

62. Hasan, S.; Ukkusuri, S.; Gladwin, H.; Murray-Tuite, P. Behavioral model to understand household-level hurricane evacuation decision making. J. Transp. Eng. 2010, 137, 341-348.

63. Baker, E.J. Hurricane evacuation behavior. Int. J. Mass Emerg. Disasters 1991, 9, 287-310.

64. Drabek, T.E. Understanding disaster warning responses. Soc. Sci. J. 1999, 36, 515-523.

65. Dash, N.; Gladwin, H. Evacuation Decision Making and Behavioral Responses: Individual and Household. Nat. Hazards Rev. 2007, 8, 69-77. 
66. De Jong, M.; Helsloot, I. The effects of information and evacuation plans on civilian response during the National Dutch flooding exercise 'Waterproef'. Procedia Eng. 2010, 3, 153-162.

67. Carnegie, J.; Deka, D. Using hypothetical disaster scenarios to predict evacuation behavioral response. In Proceedings of the Transportation Research Board 89th Annual Meeting, Washington, DC, USA, 10-14 January 2010.

68. Hasan, S.; Mesa-Arango, R.; Ukkusuri, S. A random-parameter hazard-based model to understand household evacuation timing behavior. Transp. Res. Part C 2013, 27, 108-116.

69. Kalafatas, G.; Peeta, S. Planning for evacuation: insights from an efficient network design model. J. Infrastruct. Syst. 2009, 15, 21-30.

70. Xie, C.; Lin, D.Y.; Waller, S.T. A dynamic evacuation network optimization problem with lane reversal and crossing elimination strategies. Transp. Res. Part E 2010, 46, 295-316.

71. Edara, P.; Sharma, S.; McGhee, C. Development of a large-Scale traffic simulation model for hurricane evacuation-Methodology and lessons learned. Nat. Hazards Rev. 2010, 11, 127-139.

72. Pel, A.J.; Hoogendoorn, S.P.; Bliemer, M.C.J. Impact of variations in travel demand and network supply factors for evacuation studies. Transp. Res. Rec. 2011, 2196, 45-55.

73. Mileti, D.S.; Sorensen, J.H.; O’Brien, P.W. Toward an explanation of mass care shelter use in evacuations. Int. J. Mass Emerg. Disasters 1992, 10, 25-42.

74. Chen, B. Modeling Destination Choice in Hurricane Evacuation with an Intervening Opportunity Model. Ph.D. Thesis, Louisiana State University, Baton Rouge, LA, USA, 2005.

75. Transportation Research Board. Highway Capacity Manual; Transportation Research Board: Washington, DC, USA, 2000.

76. Ewing, R. Monroe County Hurricane Evacuation Clearance Time-Final Report; Technical Report; University of Utah, Department of City \& Metropolitan Planning: Salt Lake City, UT, USA, 2010.

77. Van Delden, P.; Penton, S.; Haniff, A. Typical hourly traffic distribution for noise modelling. Can. Acoust. 2008, 36, 60-61.

(C) 2017 by the authors. Licensee MDPI, Basel, Switzerland. This article is an open access article distributed under the terms and conditions of the Creative Commons Attribution (CC BY) license (http://creativecommons.org/licenses/by/4.0/). 